\title{
Strong Quasi-Stationary Wintertime Atmospheric Surface Pressure Anomalies Drive a Dipole Pattern in the Subantarctic Mode Water Formation
}

\author{
Ivana CerovečKi ${ }^{\mathrm{a}}$ AND Andrew J. S. MeiJers ${ }^{\mathrm{b}}$ \\ ${ }^{\text {a }}$ Scripps Institution of Oceanography, La Jolla, California \\ ${ }^{\mathrm{b}}$ British Antarctic Survey, Cambridge, United Kingdom
}

(Manuscript received 31 July 2020, in final form 16 December 2020)

\begin{abstract}
The deepest wintertime (July-September) mixed layers associated with Subantarctic Mode Water (SAMW) formation develop in the Indian and Pacific sectors of the Southern Ocean. In these two sectors the dominant interannual variability of both deep wintertime mixed layers and SAMW volume is an east-west dipole pattern in each basin. The variability of these dipoles is strongly correlated with the interannual variability of overlying winter quasi-stationary mean sea level pressure (MSLP) anomalies. Anomalously strong positive MSLP anomalies are found to result in the deepening of the wintertime mixed layers and an increase in the SAMW formation in the eastern parts of the dipoles in the Pacific and Indian sectors. These effects are due to enhanced cold southerly meridional winds, strengthened zonal winds, and increased surface ocean heat loss. The opposite occurs in the western parts of the dipoles in these sectors. Conversely, strong negative MSLP anomalies result in shoaling (deepening) of the wintertime mixed layers and a decrease (increase) in SAMW formation in the eastern (western) regions. The MSLP variabilities of the Pacific and Indian basin anomalies are not always in phase, especially in years with a strong El Niño, resulting in different patterns of SAMW formation in the western versus eastern parts of the Indian and Pacific sectors. Strong isopycnal depth and thickness anomalies develop in the SAMW density range in years with strong MSLP anomalies. When advected eastward, they act to precondition downstream SAMW formation in the subsequent winter.
\end{abstract}

KEYWORDS: Atmosphere-ocean interaction; Oceanic mixed layer; Interannual variability; Oceanic variability

\section{Introduction}

Subantarctic Mode Water (SAMW) is a voluminous water mass formed in winter, predominantly by atmospheric cooling and ocean heat loss, that triggers convection on the equatorward side of the Subantarctic Front (SAF) on the northern flank of the Antarctic Circumpolar Current (ACC). This forms deep, vertically well-mixed surface layers that are subsequently advected away from their ventilation regions into the ocean interior, forming SAMW (McCartney 1977, 1982) (Fig. 1a). SAMW formation and export are part of the global overturning circulation, playing a fundamental role in the oceanic uptake and global distribution of heat, freshwater, nutrients, and dissolved gases such as oxygen and carbon dioxide (Wong et al. 1999; Sarmiento et al. 2004; Sabine et al. 2004). The SAMWs are not homogeneous in space, but instead form modes of SAMW with distinct properties (Koch-Larrouy et al. 2010; Sallée et al. 2010a; Herraiz-Borreguero and Rintoul 2011), becoming progressively colder, fresher, and denser from the western Indian Ocean to the southeast Pacific (McCartney 1977, 1982). They subduct north of the SAF from formation "hotspots," primarily in the Indian and Pacific sectors, and are subsequently exported to the subtropics following distinct pathways influenced by topography (Koch-Larrouy et al. 2010; Herraiz-Borreguero and Rintoul 2011; Jones et al. 2016).

The global Argo program of profiling floats provided for the first time near-global coverage of temperature and salinity in the upper $2000 \mathrm{~m}$, revealing that the basinwide spatial pattern of interannual and decadal SAMW variability is not spatially uniform within the individual sectors of the Southern Ocean (Sallée

Corresponding author: Ivana Cerovečki, icerovecki@ucsd.edu et al. 2010a; Gao et al. 2018; Cerovečki et al. 2019; Meijers et al. 2019; Tamsitt et al. 2020; Portela et al. 2020). Using Argo profiling floats data, Sallée et al. (2010a) showed that zonally asymmetric, large-scale mixed layer depth (MLD) anomalies develop in response to the dominant mode of atmospheric variability in the Southern Hemisphere, the southern annular mode (SAM). During positive SAM (+SAM) events the MLD anomalies form a roughly zonal wave 3 (ZW3) pattern with MLD deepening in the eastern Indian Ocean $\left(100^{\circ}-140^{\circ} \mathrm{E}\right)$ and the central Pacific Ocean $\left(100^{\circ}-140^{\circ} \mathrm{W}\right)$, and with a MLD shoaling in the western Pacific Ocean $\left(140^{\circ} \mathrm{E}-140^{\circ} \mathrm{W}\right)$. Conversely, negative SAM (-SAM) events drive an opposite MLD response (Sallée et al. 2010a). During both positive and negative SAM events the MLD variability can be up to $\pm 100 \mathrm{~m}$. However, due to relatively short time period of the available observations (2002-09), Sallée et al. (2010a) did not obtain significant results for the effects of El Niño-Southern Oscillation (ENSO) on the MLD distribution. Analyzing SAMW in the Pacific sector using a longer Argo record, 2005-18, Meijers et al. (2019) showed that both SAM and ENSO have similar impacts on SAMW thickness, and that its variability is strongly influenced by the relative phase of the SAM and ENSO. The SAMW thickness in the eastern (central) Pacific is strongly positively (negatively) correlated with both the SAM and ENSO (Meijers et al. 2019). Consequently the SAMW thicknesses in the eastern and central Pacific vary predominantly out of phase with one another, with an interannual variability of up to $\pm 150 \mathrm{~m}$. This variability is caused not only by the variability of local atmospheric forcing, but also by remote effects by advection, both of which are associated with the major climate modes of variability of the Southern Ocean in the Pacific sector (Meijers et al. 2019). 


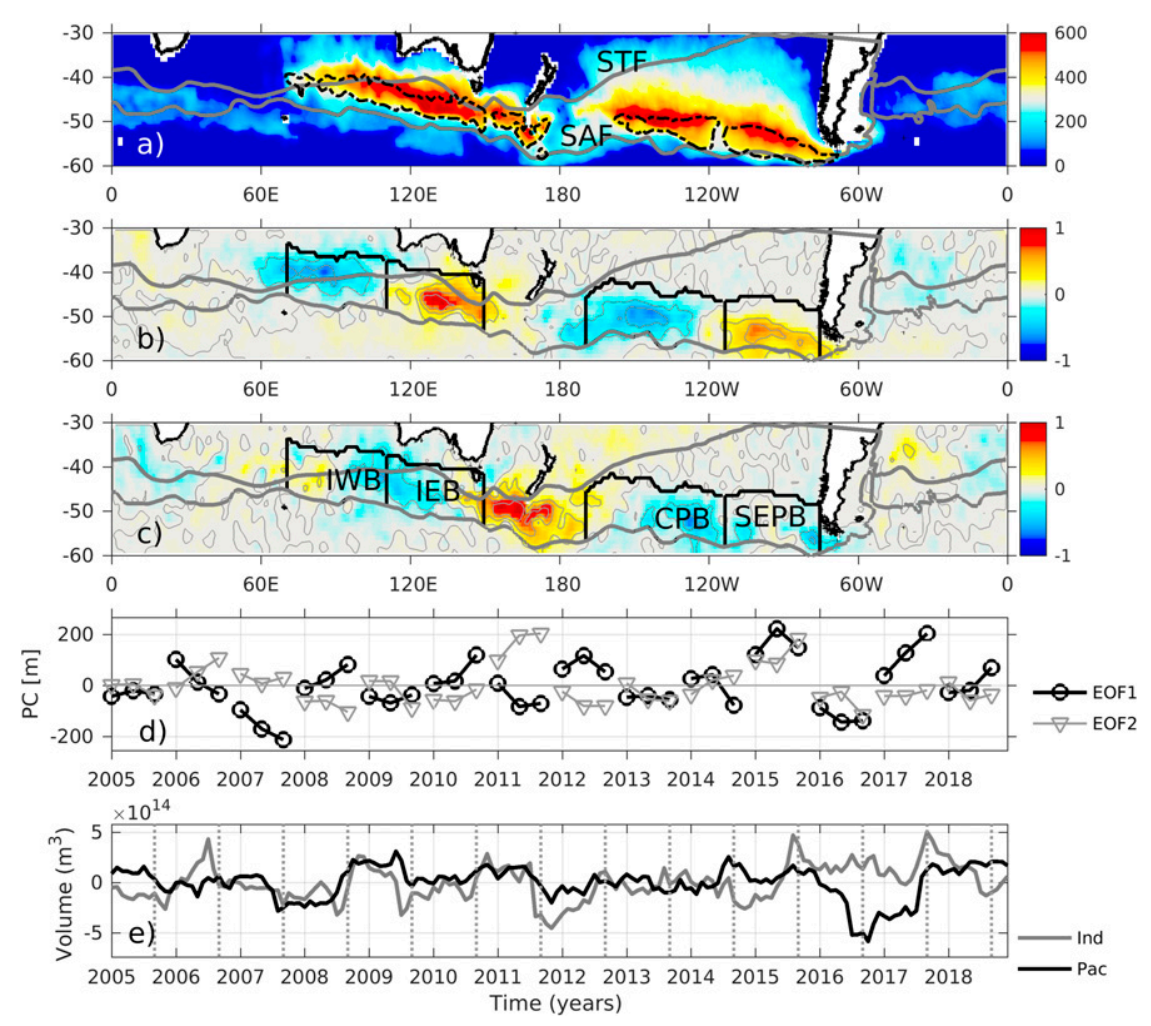

FIG. 1. (a) Wintertime (July-September) SAMW thickness $\left(\sigma_{\theta}=26.6-27.1 \mathrm{~kg} \mathrm{~m}^{-3}\right.$, with PV $<$ $\left.40 \times 10^{-12} \mathrm{~m}^{-1} \mathrm{~s}^{-1}\right)$, time averaged over years 2005-18. The thick black dash-dotted contour shows September monthly mean mixed layer depth (MLD) of $300 \mathrm{~m}$. MLD has been computed as the depth at which the potential density has increased by $0.03 \mathrm{~kg} \mathrm{~m}^{-3}$ from its surface value. Also shown are normalized spatial variance maps of (b) the first EOF (EOF1) and (c) the second EOF (EOF2) mode of wintertime MLD that has been detrended, with the seasonal signal removed. (d) The associated monthly mean principal components (PCs); EOF1 (EOF2) explains $20.2 \%$ (11.0\%) of the variance. (e) The difference between the monthly mean SAMW volume in the IEB minus IWB (gray) and SEPB minus CPB (black) with the time mean volume difference of IEB minus IWB and SEPB minus CPB removed. The SAMW density range considered in each box is given in the text and Fig. 3. All data are from the RG-Argo. In (b) and (c) the contour interval is 0.25 , and the black boxes encompass the main SAMW formation regions: the Indian west box (IWB) $70^{\circ}-110^{\circ} \mathrm{E}$, Indian east box (IEB) $110^{\circ}-150^{\circ} \mathrm{E}$, central Pacific box (CPB) $170^{\circ}-114^{\circ} \mathrm{W}$, and southeast Pacific box (SEPB) $114^{\circ}-75^{\circ} \mathrm{W}$, all in the latitude band $12^{\circ}$ north of the Subantarctic Front (SAF) as defined by Orsi et al. (1995). Gray lines show the SAF and Subtropical Front (STF) defined by Orsi et al.

Tamsitt et al. (2020) analyzed the interannual variability of wintertime air-sea heat loss and MLDs using observations from two high-latitude Southern Ocean moorings. The moorings were located in key SAMW formation regions in the southeast Pacific and in the southeast Indian Ocean. These observations revealed that the interannual variability of wintertime ocean heat loss and of MLDs was often in phase between the two mooring locations, especially in years when wintertime MLDs were anomalously deep. This covariability between the Pacific and Indian sectors was shown to be associated with the global ZW3 pattern noted by Sallée et al. (2010a), resulting in strong zonal dipoles in wintertime surface ocean heat loss anomalies and MLD anomalies in both the Indian and Pacific sectors. Using a gridded Argo product, Lu et al. (2020, manuscript submitted to Nat. Comm.) showed that such interannual variability of MLD and SAMW thickness is advected eastward by the ACC, re-emerging the next winter in the next dipole center downstream where the airsea fluxes make it colder and denser. This provides a multiyear component to the variability superimposed on the interannual changes due to air-sea fluxes.

Significant changes of SAMW properties have also been observed on a longer time scale. Argo data showed that between 2005 and 2015, SAMW thickened $\left(3.6 \pm 0.3 \mathrm{~m} \mathrm{yr}^{-1}\right)$, deepened $\left(2.4 \pm 0.2 \mathrm{~m} \mathrm{yr}^{-1}\right)$, and warmed $\left(3.9 \pm 0.3 \mathrm{~W} \mathrm{~m}^{-2}\right)$ (Gao et al. 2018). Much of the upper ocean heat content increase observed during this time period was in the SAMW density range, primarily caused by changes in SAMW thickness and volume, while changes of SAMW temperature played a much smaller role (Gao et al. 2018). Similarly, Meijers et al. (2019) also showed that on interannual time scales the net SAMW heat content in the South Pacific is governed by the variability in SAMW thickness, rather than variability in its temperature. 


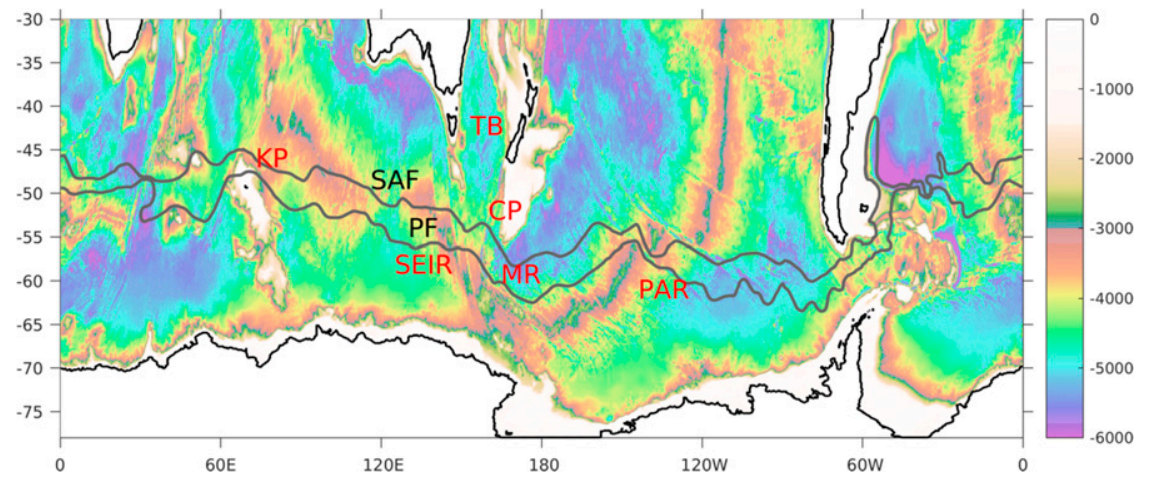

FIG. 2. Southern Ocean topography: Kerguelen Plateau (KP), Southeast Indian Ridge (SEIR), Tasman Basin (TB), South Tasman Rise (STR), Campbell Plateau (CP), Macquarie Ridge (MR), and Pacific Antarctic Ridge (PAR). Thick gray lines show the SAF and the Polar Front (PF) defined by Orsi et al. (1995).

This work builds on the results of these recent studies. We analyze the atmospheric processes that play an important role in driving the strong interannual variability of deep wintertime (defined here as July-September) MLDs in the Southern Ocean. We focus on the role of the interannual variability of wintertime mean sea level pressure (MSLP) that has a large variance in the Southern Ocean (Hobbs and Raphael 2010). Since the interannual variability of SAMW is driven not only by local but also by advective processes (Meredith et al. 2008; Cerovečki et al. 2019; Meijers et al. 2019; Lu et al. 2020, manuscript submitted to Nat. Comm.), we additionally consider the role of advection in setting the interannual SAMW variability in the Indian and Pacific sectors.

Data used in this work are described in section 2. Results are presented in section 3 where we define SAMW for this study and its four primary formation regions, and describe the interannual variability of SAMW and deep wintertime mixed layers. We describe the interannual variability of monthly MSLP anomalies in austral winter and contrast these with the atmospheric and oceanic conditions in winters with strong positive and strong negative MSLP anomalies overlying SAMW formation regions. We examine the relationship between SAM and ENSO and the wintertime anomalies of MSLP, the net surface air-sea heat flux, and the SAMW thickness. Furthermore, in order to address the importance of advective processes in modifying the SAMW properties, we consider the time-longitude diagrams of the isopycnal depth, thickness, and temperature anomalies in the SAMW density range. A discussion of the results and conclusions are given in section 4 .

\section{Tools and methods}

We primarily analyze the gridded hydrography created by Roemmich and Gilson (2009) by optimally interpolating qualitycontrolled Argo profiles. These data are available at http://sioargo.ucsd.edu/RG_Climatology.html, with a $1^{\circ} \times 1^{\circ}$ horizontal resolution, 58 nonuniformly spaced vertical levels, as monthly means. We focus on the time period 2005-18, as prior to this the Argo data were too sparse to accurately capture water mass variability. The SAMW representation in this dataset has already been thoroughly evaluated in Cerovečki et al. (2019) where it has been shown to accurately reproduce the interannual SAMW variability in the Pacific sector when compared to the "raw" Argo profiles. The disadvantage of using this dataset for water mass analysis is that mapping of Argo profiles has been done onto vertical (rather than pressure or isopycnal) levels, potentially "smearing" water masses where isopcynals steeply slope. Also, where insufficient Argo data were available for mapping, values at grid points were relaxed to climatological values, potentially reducing the interannual variability.

To examine the drivers of variability within the gridded hydrographic products we also use the atmospheric fields (MSLP, wind stress, air temperature, and net air-sea heat flux) from the European Centre for Medium-Range Weather Forecasts (ECMWF) ERA5 reanalysis (ECMWF 2017) for the same time period. These atmospheric reanalysis fields also form the basis for similar analysis in Cerovečki et al. (2019) and Meijers et al. (2019).

\section{Results}

\section{a. Defining $S A M W$ and the interannual variability of wintertime mixed layer depths}

As a first step to examining MLD variability we carry out an empirical orthogonal function (EOF) analysis of wintertime (July-September) MLDs in the Southern Ocean. The EOF analysis provides maps of the time independent patterns of variability (Figs. 1b,c), while the principal components describe the time variability of this pattern, in our case during the winter months July-September from 2005 to 2018 (Fig. 1d).

The EOF1 shows two regions of deep wintertime mixed layers that exhibit out-of-phase temporal variability, forming one dipole in the Pacific sector and the other dipole in the Indian sector of the Southern Ocean (Fig. 1b). In the Pacific sector, the two regions of the dipole are separated by the Pacific Antarctic Ridge, located at approximately $115^{\circ} \mathrm{W}$ (Figs. 1b,d and 2). This pattern aligns closely with the two pools of Pacific SAMW variability described by Meijers et al. (2019). As in the Pacific sector, the location of deep wintertime mixed 
layers in the Indian sector is also strongly influenced by topography (Herraiz-Borreguero and Rintoul 2011; Sallée et al. 2010b). The deep mixed layers that extend from the Kerguelen Plateau $\left(70^{\circ} \mathrm{E}\right)$ to the Campbell Plateau $\left(170^{\circ} \mathrm{E}\right)$, (Fig. 2) form another dipole similar in size and structure to that noted by Tamsitt et al. (2020) and Lu et al. (2020, manuscript submitted to Nat. Comm.). In both ocean sectors the deepest wintertime mixed layers are located in the approximately $12^{\circ}$ wide latitude band north of the SAF (Figs. 1b,c) and exhibit strong interannual variability of up to $\pm 200 \mathrm{~m}$ (Figs. 1a-d). In the Atlantic sector, where wintertime mixed layers are much shallower, the interannual variability is accordingly much smaller (Figs. 1ad). EOF analyses were also conducted for the Pacific and Indian sectors separately, and produced EOF1 patterns very similar to the global pattern in Fig. 1b (not shown). Along with the agreement with previous regional studies on centers of MLD variability this suggests a degree of covariance between the basins (see later discussion).

A dominant feature of the EOF2 is the variability of deep winter mixed layers located south of New Zealand, southwest of the Campbell Plateau $\left(160^{\circ}-170^{\circ} \mathrm{E}\right)$ (Fig. 1c). It is less clear that this is as physically meaningful as EOF1 but may represent the uncorrelated component of overlapping variability in the two basins or spatial viability from interaction with the Tasman Sea. This pool is physically separate from the upstream pool in much the same way the Pacific Antarctic Ridge separates the Pacific pools so differing modes of variability are not physically unreasonable (Fig. 2). We confine subsequent analysis to the regions highlighted by the EOF1 and previous studies.

Similar to Cerovečki et al. (2019) and Meijers et al. (2019) we next define the boxes encircling the individual geographical regions with coherent deep wintertime mixed layer variability as the following: the central Pacific box (CPB) $170^{\circ}-114^{\circ} \mathrm{W}$, the southeast Pacific box (SEPB) $114^{\circ}-75^{\circ} \mathrm{W}$, the Indian west box (IWB) $70^{\circ}-$ $110^{\circ} \mathrm{E}$, and the Indian east box (IEB) $110^{\circ}-150^{\circ} \mathrm{E}$. All four boxes are $12^{\circ}$ in meridional extent, and located north of the SAF (Fig. 1c). Hereafter we refer to these four regions as the SAMW boxes.

The SAMW density range in each of the four SAMW boxes was obtained by considering the density distribution of the volume of low potential vorticity $(\mathrm{PV})$ water $\left(\mathrm{PV}<40 \times 10^{-12} \mathrm{~m}^{-1} \mathrm{~s}^{-1}\right)$ in each box (Fig. 3). Hereafter, "low PV" refers to PV $<40 \times$ $10^{-12} \mathrm{~m}^{-1} \mathrm{~s}^{-1}$, where PV is defined as PV $=\left(f / \rho_{0}\right)\left(\partial \sigma_{\theta} / \partial z\right)$. Here $f$ is the Coriolis parameter, $\rho_{0}$ is the density of seawater, and $\sigma_{\theta}$ is the potential density (taken here to be defined relative to the surface). The SAMW is thus defined as the low PV water in the following $\sigma_{\theta}$ range: $26.6-26.85 \mathrm{~kg} \mathrm{~m}^{-3}$ in the IWB, $26.7-26.9 \mathrm{~kg} \mathrm{~m}^{-3}$ in the IEB, $26.825-26.975 \mathrm{~kg} \mathrm{~m}^{-3}$ in the CPB, and $26.925-27.05 \mathrm{~kg} \mathrm{~m}^{-3}$ in the SEPB (Figs. 3a,b). The results that are shown here are robust and insensitive to small variations in density or PV limits.

Using this SAMW definition, we consider the interannual variability of the volume of newly formed SAMW in each of the four SAMW boxes. Following Davis et al. (2011), the volume of newly formed SAMW in year $i$ was approximated by the difference between the volume maximum at the end of the austral winter-spring formation season in year $i$ and the volume minimum in the previous year (Figs. 3c,d). In agreement with the zonal dipole pattern of the wintertime MLD variability (Fig. 1b), in years when the volume of the newly formed SAMW is large in one of the two boxes in the
Indian (or Pacific) sector, the volume of newly formed SAMW in the other box of the same ocean sector tends to be small (Figs. 3c,d). The correlation coefficient between the volume of the newly formed SAMW in the IWB and IEB is -0.59 , while the correlation coefficient between the volume of the newly formed SAMW in the CPB and SEPB is -0.34 . The correlations are relatively weak because it is only in some years (with strong MSLP anomalies) that there are notable opposite signals.

Meijers et al. (2019) attributed such out-of-phase variability of the SAMW thickness in the Pacific sector to the change in conditions associated with changes in SAM and ENSO. During the time periods $2005-08$ and $2012-17$ the difference in the SAMW thickness in the two SAMW boxes in the Pacific sector was large, due to in-phase reinforcing conditions associated with the SAM and ENSO modes. In contrast, between 2008 and 2012 out of phase SAM and ENSO resulted in less coherent patterns of SAMW variability in these two boxes (Meijers et al. 2019). The same temporal variability is evident in the time series of the volume of newly formed water. In the CPB and SEPB the variability of the volume of newly formed water tends to be out of phase in 2005-08 and 2012-17, and generally in phase in 2008-12 (Fig. 3d). Similarly, in the IWB and IEB the variability of the volume of the newly formed SAMW tends to be out of phase in 2005-08 and 2010-17, and in phase in 2008-10 (Fig. 3c).

To quantify the interannual variability of the volume of the newly formed water for each region considered in Figs. 3c-e we estimate its time average (over years 2006-18) and the standard deviation. We additionally express the variability (represented by a standard deviation) as a percentage of the time mean volume of the newly formed water in each region. In the IWB the volume of the newly formed water was $(7.7857 \pm 1.2623) \times 10^{14} \mathrm{~m}^{3}(16.2 \%$ variability), slightly higher than in the IEB $[(6.5970 \pm 1.4181) \times$ $10^{14} \mathrm{~m}^{3} ; 21.5 \%$ variability]. Variability is even stronger in the CPB $\left[(5.1305 \pm 1.3313) \times 10^{14} \mathrm{~m}^{3} ; 25.9 \%\right.$ variability $]$, while the variability during this time period was the strongest in the SEPB $\left[(3.0422 \pm 1.3156) \times 10^{14} \mathrm{~m}^{3} ; 43.24 \%\right.$ variability $]$. Considering the entire Indian sector $\left(70^{\circ}-160^{\circ} \mathrm{E}\right)$ and the Pacific sector $\left(160^{\circ} \mathrm{E}-\right.$ $75^{\circ} \mathrm{W}$, both in the latitude range south of $30^{\circ} \mathrm{S}$ ), the variability was much smaller: $(15.4385 \pm 1.6073) \times 10^{14} \mathrm{~m}^{3}(10.4 \%)$ in the Indian sector and $(12.527 \pm 1.8525) \times 10^{14} \mathrm{~m}^{3}(14.8 \%)$ in the Pacific sector. Thus, the interannual variability of the net volume of the newly formed SAMW, summed over the two boxes of the same ocean sector (Indian or Pacific), is much weaker (Fig. 3e), masking much of the dipole variability within each sector.

The interannual variability of the SAMW volume in the two dipoles in the Indian and Pacific sector is often, but not always, in phase between basins. This is illustrated in Fig. 1e showing the difference between the SAMW volume in the two boxes in the Indian and Pacific sectors (shown as the SAMW volume in the east box minus the SAMW volume in the west box of the same sector) (Fig. 1e). The most notable departure occurs at the end of 2016 and during 2017 and is likely influenced by the strong ENSO during that time (Meijers et al. 2019).

\section{b. The interannual variability of the monthly mean sea level pressure anomalies in the Southern Ocean}

Here we examine the role of MSLP variability in driving variability in the SAMW formation regions, and examine its 

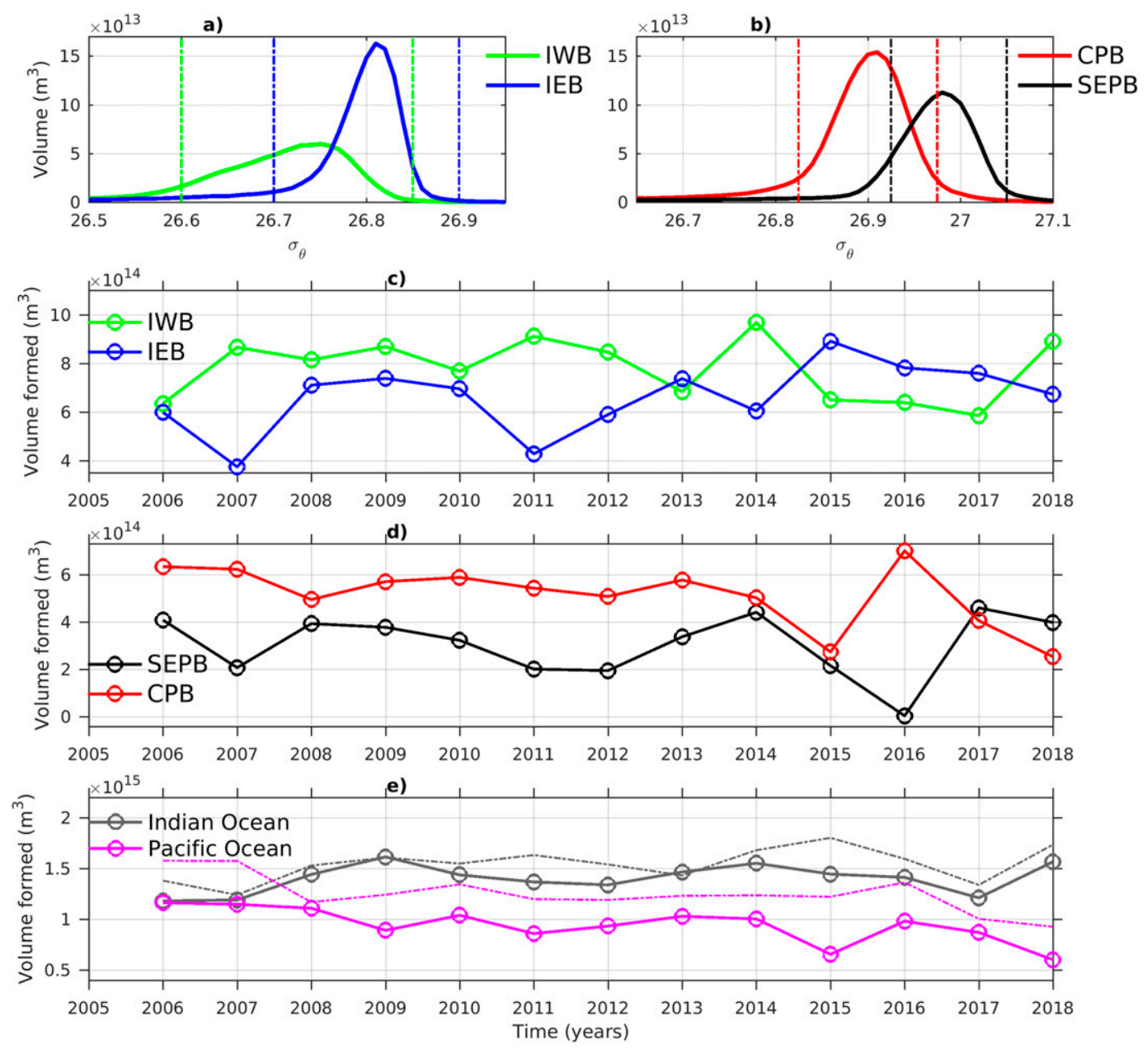

FIG. 3. SAMW properties, considering the low $\mathrm{PV}\left(\mathrm{PV}<40 \times 10^{-12} \mathrm{~m}^{-1} \mathrm{~s}^{-1}\right)$ water. (a) Density distribution of 2005-18 time mean volume in the IWB and the IEB. (b) As in (a), but for the CPB and SEPB. (c) Volume of newly formed SAMW each year separately in each of the two boxes in the Indian sector considering the $\sigma_{\theta}$ range 26.6$26.85 \mathrm{~kg} \mathrm{~m}^{-12}$ in the IWB, and $26.7-26.9 \mathrm{~kg} \mathrm{~m}^{-3}$ in the IEB. (d) As in (c), but for the two boxes in the Pacific sector considering the $\sigma_{\theta}$ range $26.825-26.975 \mathrm{~kg} \mathrm{~m}^{-3}$ in the CPB, and $26.925-27.05 \mathrm{~kg} \mathrm{~m}^{-3}$ in the SEPB. (e) As in (c), except considering SAMW volume in both boxes in the (black) Indian sector, in the $\sigma_{\theta} 26.6-26.9 \mathrm{~kg} \mathrm{~m}^{-3}$ range and (magenta) Pacific sector, in the $\sigma_{\theta} 26.825-27.05 \mathrm{~kg} \mathrm{~m}^{-3}$ range (shown with the solid line; dashed lines are as solid lines, except considering the latitude range south of $30^{\circ} \mathrm{S}$, and longitude ranges $70^{\circ}-160^{\circ} \mathrm{E}$ for the Indian sector and $160^{\circ} \mathrm{E}-75^{\circ} \mathrm{W}$ for the Pacific sector). Following Davis et al. (2011), the volume of newly formed low PV water in year $i$ was estimated as the difference between the volume maximum at the end of the austral winter-spring formation season in year $i$ and the volume minimum in the previous year. All data are from RG-Argo.

relationship to atmospheric modes such as the SAM and ENSO. Although the extratropical circulation in the Southern Hemisphere is strongly zonally symmetric, there are also significant asymmetries, mostly associated with quasi-stationary zonal waves. The long-term mean zonal pressure anomalies are very successfully represented as a superposition of the zonal wavenumbers 1 and 3 (ZW1 and ZW3) (van Loon and Jenne 1972). Although ZW1 is the dominant wave, the variation of ZW3 is important because of its potential impact on the regional meridional circulation and northward (southward) transport of colder (warmer) air (Raphael 2004) and its subsequent impact on surface ocean properties. Unlike the situation at these multiannual time scales, at shorter time scales, such as monthly, the zonal wave pattern is not as well defined. Instead, the monthly mean pressure field is dominated by two quasi-stationary anticyclones, whose strength seems to be related to $\mathrm{ZW} 1$, and whose longitude seems to be related to ZW3 (Hobbs and Raphael 2010).

The eastern anticyclone is centered somewhat to the east of the Drake Passage, and the western anticyclone is located south of the New Zealand (Hobbs and Raphael 2010) (Fig. 4a). The standard deviation of the wintertime monthly averages of the MSLP reveals several centers of enhanced variability in the latitude range encompassing the SAMW formation regions 

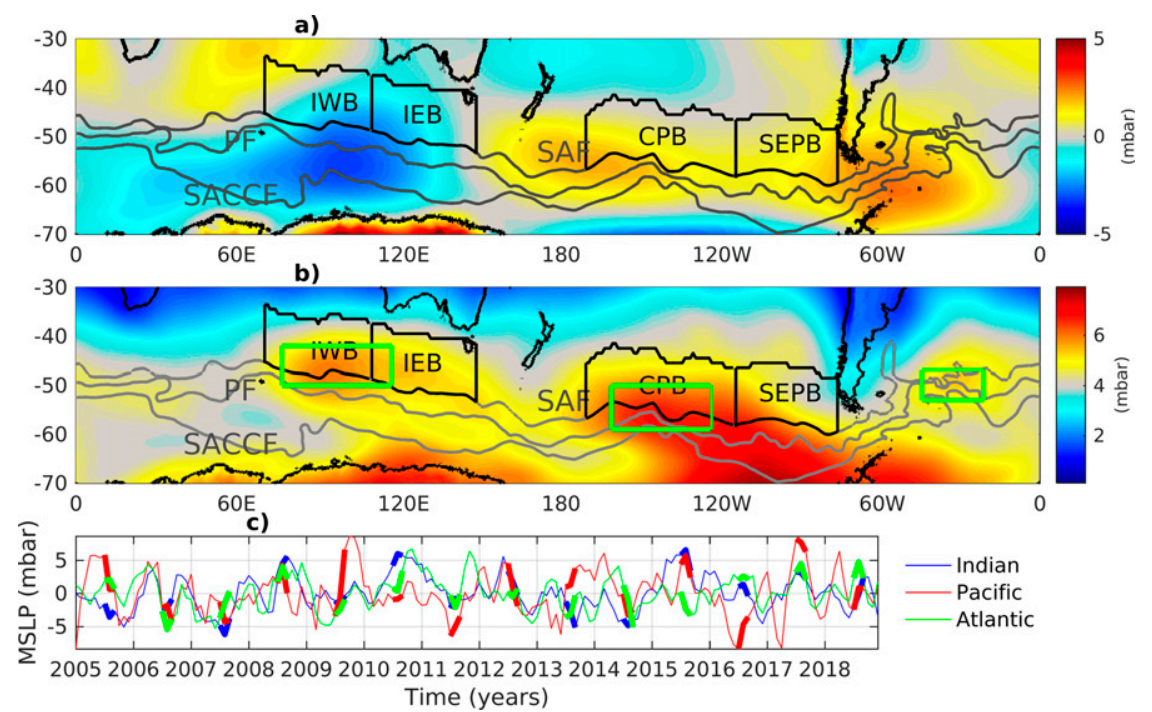

FIG. 4. (a) The zonal anomaly of the monthly averages of the mean sea level pressure (MSLP) in winter (July-September) and (b) the standard deviation of the individual monthly averages of MSLP in winter (July-September), with the seasonal signal removed; both (a) and (b) consider the time period 2005-18. The three green boxes encircling regions with enhanced MSLP variability north of the SAF with coordinates $77^{\circ}-118^{\circ} \mathrm{E}, 42^{\circ}-50^{\circ} \mathrm{S} ; 160^{\circ}-123^{\circ} \mathrm{W}, 50^{\circ}-$ $59^{\circ} \mathrm{S}$; and $44^{\circ}-21^{\circ} \mathrm{W}, 47^{\circ}-53^{\circ} \mathrm{S}$. Heavy black lines in (a) and (b) show the position of the four SAMW boxes shown in Fig. 1 (in mbar; $1 \mathrm{mbar}=1 \mathrm{hPa}$ ). (c) Three-point averaged monthly mean MSLP anomaly (with the seasonal signal and 2005-18 time mean removed), averaged over the region of the three boxes shown in (b), where heavy lines indicate wintertime (JulySeptember) monthly mean values. Gray lines in (a) and (b) show the SAF, PF, and Southern Antarctic Circumpolar Current Front (SACCF) defined by Orsi et al. (1995). Thick black lines show the four main SAMW formation regions: IWB, IEB, CPB, and SEPB.

and immediately to their south (Fig. 4b). The variability is particularly strong in the Amundsen, Bellingshausen, and Ross Seas, which constitute the West Antarctic pole of interannual MSLP variability (Connolley 1997). However, because this region of strong variability is located farther poleward than the southern boundary of the RG-Argo dataset (our primary dataset), in what follows we focus only on the centers of the enhanced MSLP variability located equatorward of the SAF, but note that this poleward variability can influence SAMW formation in the southeast Pacific (Close et al. 2013; Naveira Garabato et al. 2009; Cerovečki et al. 2019).

There are three centers of enhanced MSLP variability in the SAMW formation latitude range, one in each of the three ocean sectors. The region in the central Pacific (approximately $160^{\circ}-123^{\circ} \mathrm{W}, 50^{\circ}-59^{\circ} \mathrm{S}$ ) overlaps with the $\mathrm{CPB}$, while the MSLP variability in the SEPB is much smaller, except along its southern and western edges (Fig. 4b). In the Indian sector, the MSLP variability is strong southwest of Australia (approximately $77^{\circ}-118^{\circ} \mathrm{E}, 42^{\circ}-50^{\circ} \mathrm{S}$ ), in the region that overlaps with both the IWB and IEB. In the Atlantic sector, the monthly MSLP variability is slightly enhanced in the region of approximately $44^{\circ}-21^{\circ} \mathrm{W}, 47^{\circ}-53^{\circ} \mathrm{S}$, but this variability is much weaker than in the Indian and Pacific sector (Fig. 4b). The interannual variability of wintertime MSLP in the three centers of enhanced variability is not necessarily in phase (Fig. 4c).
Hobbs and Raphael (2010) showed that although there is some covariance between the SAM and the two anticyclones that they identified, a significant percentage of the monthly MSLP variability that is unrelated to the SAM can be explained by the anticyclone time series. Here we explore the relationship between MSLP and the SAM and ENSO and their impact on the regions of high MSLP variability identified above in more detail.

The linear regression of the wintertime monthly mean MSLP on the SAM index (Marshall 2003) shows that in the +SAM phase, the MSLP is anomalously high on the equatorward side of the SAF, and anomalously low almost everywhere south of $60^{\circ} \mathrm{S}$, with an intrusion of low pressure in the eastern Pacific (Fig. 5a), (Sallée et al. 2010a). One center of enhanced MSLP variability is located in each of the three ocean sectors (Fig. 5a) and will introduce the meridional wind anomalies of the opposite sign on the two flanks of each MSLP anomaly. In a +SAM phase, the positive MSLP anomaly will strengthen northerly (southerly) winds in the western (eastern) part of each ocean sector, while also strengthening the circumpolar zonal winds poleward of the SAMW formation regions. The strongest MSLP anomaly is in the Indian sector, southwest of Australia, where the overall MSLP variance is also particularly strong (Fig. 4b), suggesting that a large fraction of the MSLP variability at this location covaries with SAM. However, the MSLP variability associated with the 

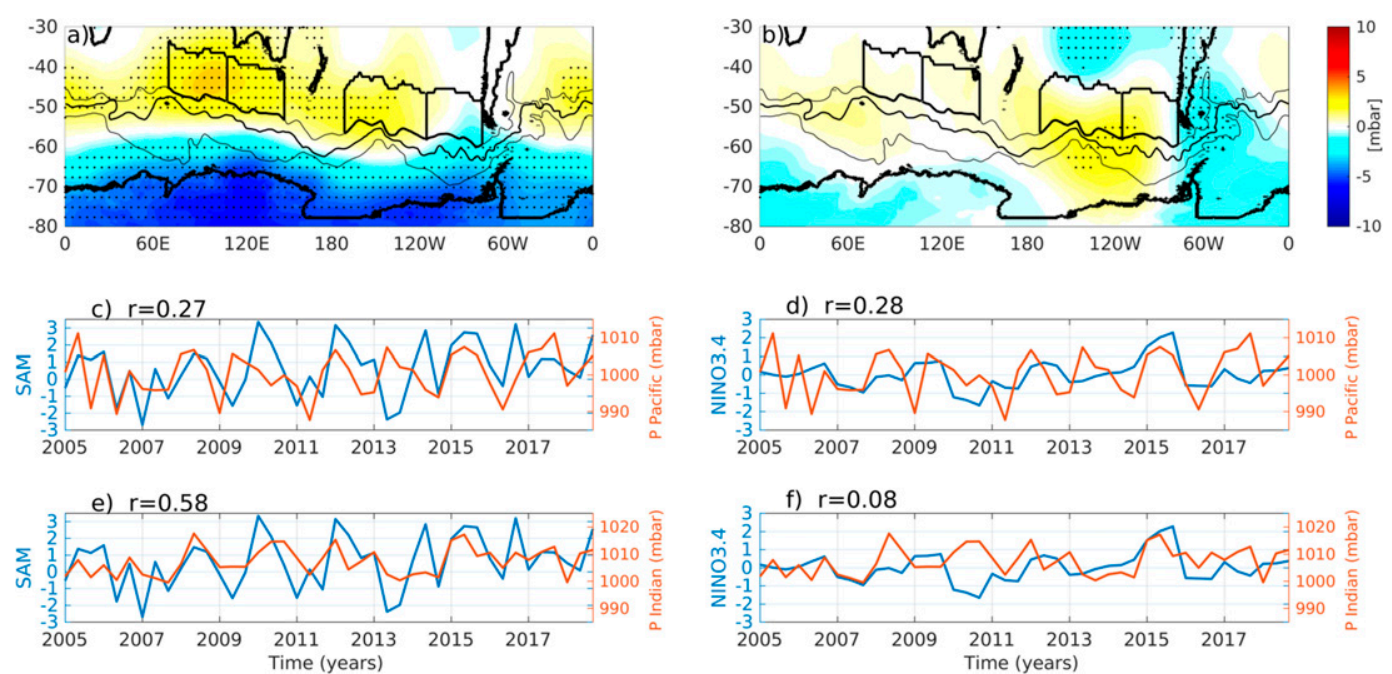

FIG. 5. The linear regression coefficients of the detrended MSLP (in mbar), with the seasonal signal removed, in winter (July-September) on (a) the SAM index, and (b) Niño-3.4 index. The time series of monthly mean wintertime (July-September) MSLP averaged over the box of high variability in the Pacific sector and (c) the SAM index and (d) the Niño-3.4 index, with the corresponding correlation coefficients indicated in the title. (e),(f) As in (c) and (d), but considering the MSLP averaged over the box of high variability in the Indian sector. Stippling indicates a statistically significant correlation at the $95 \%$ level.

wintertime SAM is weaker in the Pacific sector, where it is significant only over the CPB (Fig. 5a). Although still statistically significant, the MSLP anomaly associated with SAM is even weaker in the Atlantic sector. The correlation coefficient between the wintertime monthly mean MSLP averaged over the region of strongest MSLP variability in the Indian sector (shown as a green box in Fig. 4b) and the SAM index is 0.58 (Fig. 5e). The corresponding correlation coefficients in the
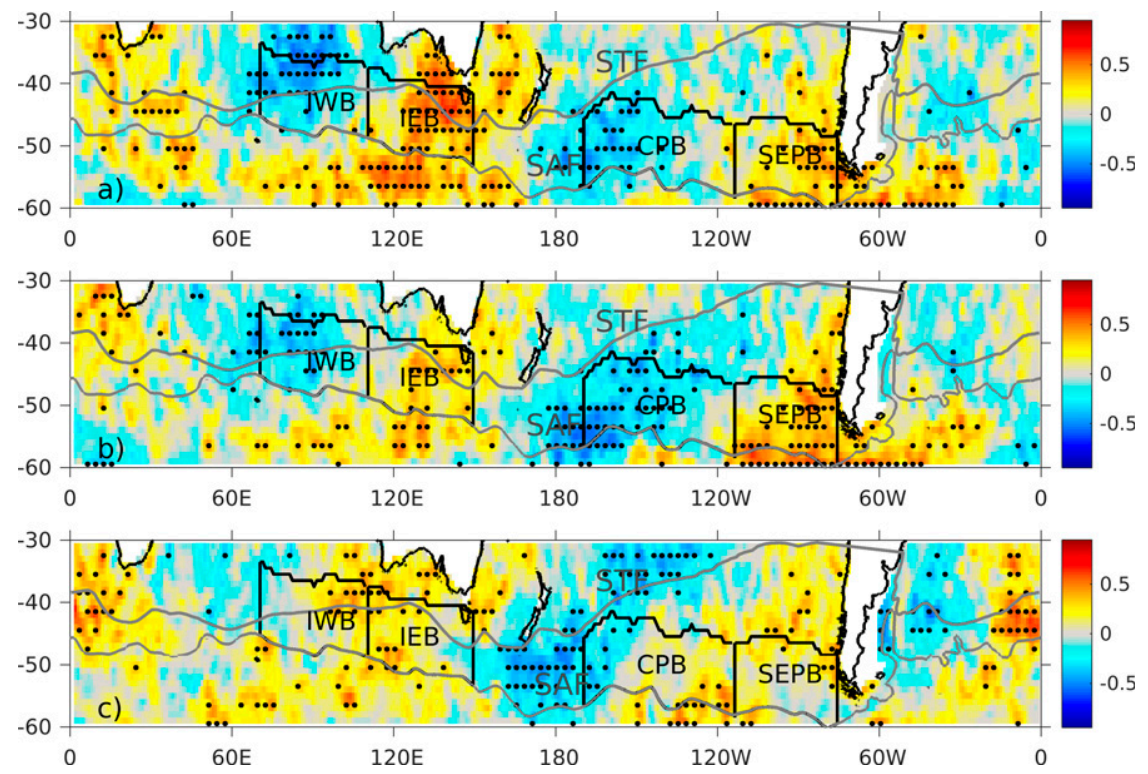

FIG. 6. Correlation between monthly mean MLD anomaly and MSLP anomalies in winter (July-September), where both anomalies were obtained as a deviation from the 2005-18 wintertime mean. The MSLP was averaged over the box of high variance located in the (a) Indian sector, (b) Pacific sector, and (c) Atlantic sector (location of the boxes is shown in Fig. 4). For both MLD and MSLP trend and seasonal signal were removed. Stippling indicates a correlation significant at the $95 \%$ level. Thick black lines show the four main SAMW formation regions: IWB, IEB, CPB, and SEPB. Gray lines show the STF and SAF defined by Orsi et al. (1995). 

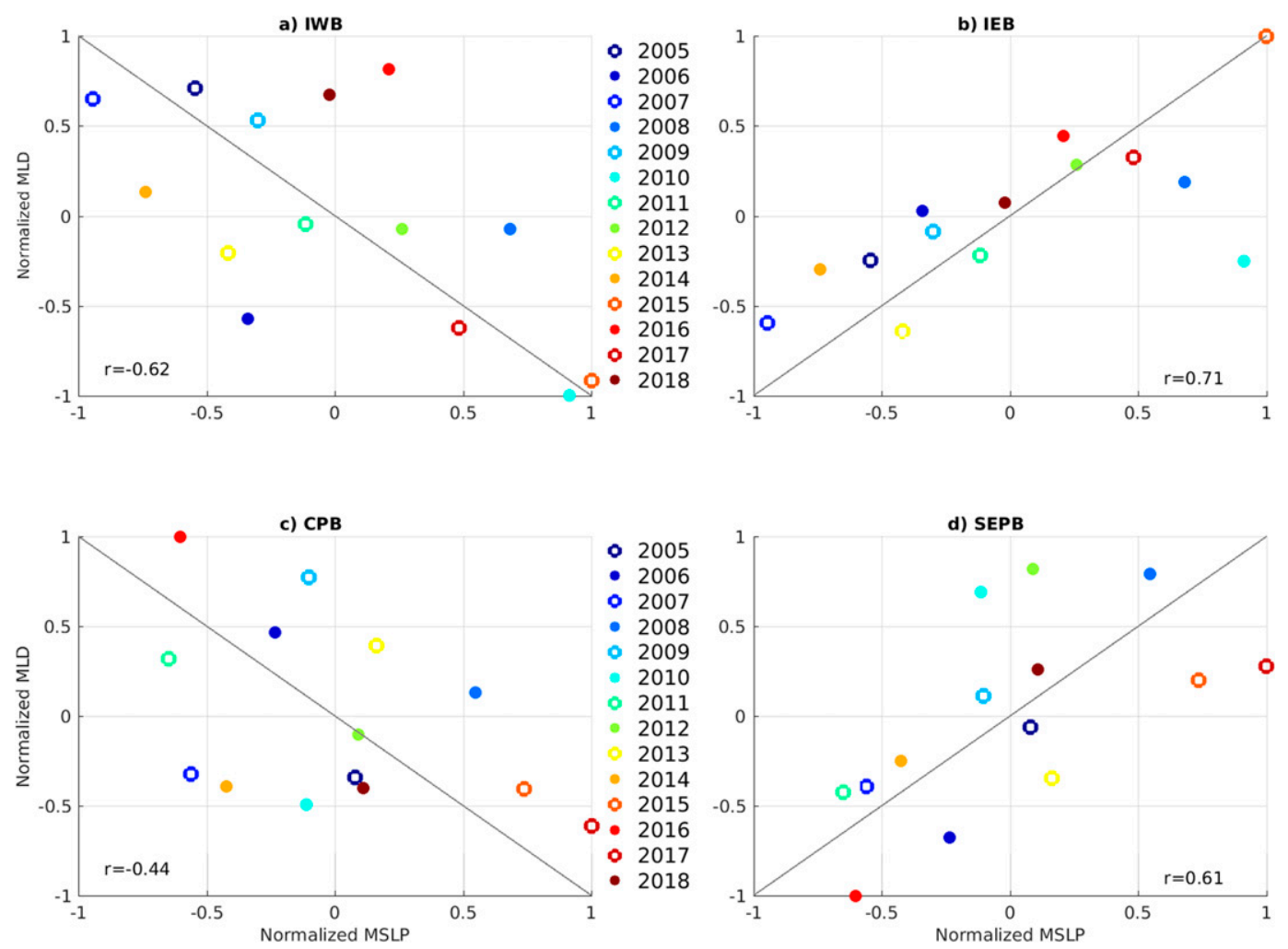

FIG. 7. The scatterplot of wintertime MLD anomalies averaged separately over each of the four SAMW formation boxes and normalized by its maximum value in each box, plotted vs wintertime MSLP anomalies averaged over the region of strongest variance in (a),(b) the Indian sector and (c),(d) the Pacific sector, where both MSLP anomalies were normalized by the maximum of its absolute value in that sector.

Pacific (0.27; Fig. 5c) and Atlantic sector (not shown) are much smaller. As expected, the linear regression of the wintertime monthly MSLP on the Niño-3.4 index is strongest in the southeast Pacific, where positive ENSO (+ENSO) events are associated with a positive wintertime MSLP anomaly centered between the two SAMW formation regions (Fig. 5b). Wind anomalies during a +ENSO will thus enhance wind anomalies associated with a positive $+\mathrm{SAM}$, strengthening southerly (northerly) winds in the SEPB (CPB) (Meijers et al. 2019). However, the infrequent nature of ENSO means that its overall correlation with the peak MSLP variability in the Pacific (shown as a green box in Fig. 4b) is quite low $(r=0.28)$.

Overall we find that while the SAM and ENSO likely contribute to the overall MSLP variability, significantly so in the case of SAM in the Indian sector, they do not explain all variability.

We now demonstrate the importance of these regional wintertime monthly MSLP anomalies in driving the wintertime MLD variability. Figure 6 shows the correlation maps between the wintertime monthly mean MSLP anomalies, averaged over each of the three regions of enhanced MSLP variability (shown as green boxes in Fig. 4b), and the monthly mean MLD anomalies. In all three correlation maps the dominant features are strong zonal dipoles evident in each of the three ocean sectors (Fig. 6). The zonal dipole patterns in the Indian and in the Pacific sector closely resemble the dipole pattern identified by the EOF1 of wintertime MLDs, (Fig. 1b), indicating that the dipole pattern of wintertime MLDs is atmospherically driven. The high degree of similarity of the correlation pattern between the MLD anomalies and the MSLP anomalies in each of the three high variance regions in Fig. 6 is indicative of covariance in the three MSLP boxes shown in Fig. 4b. Thus, although the MLDs in the Indian and Pacific sectors are controlled by the regional atmospheric anomalies, the MSLP anomalies themselves in the three ocean sectors tend to be in phase in years with strong MSLP anomalies, resulting in a more circumpolar (rather than regional) response. This also accounts for the high degree of similarity between circumpolar EOFs of MLD and EOFs of individual basins discussed earlier. Although the EOF1 of the wintertime MLDs does not show a dipole pattern in the Atlantic sector, such a pattern is evident in the correlation map between the MSLP anomaly spatially averaged over the region of high variance (green box) in the Atlantic sector (Fig. 6c) and the wintertime MLD. This is likely to be because the climatological mean wintertime MLDs in the Atlantic sector are much shallower than these in the Indian and Pacific sectors.

\section{c. Composites of wintertime atmospheric and oceanic conditions}

Despite the importance of the MSLP anomalies in driving the covariability of the wintertime MLD dipoles in all three 

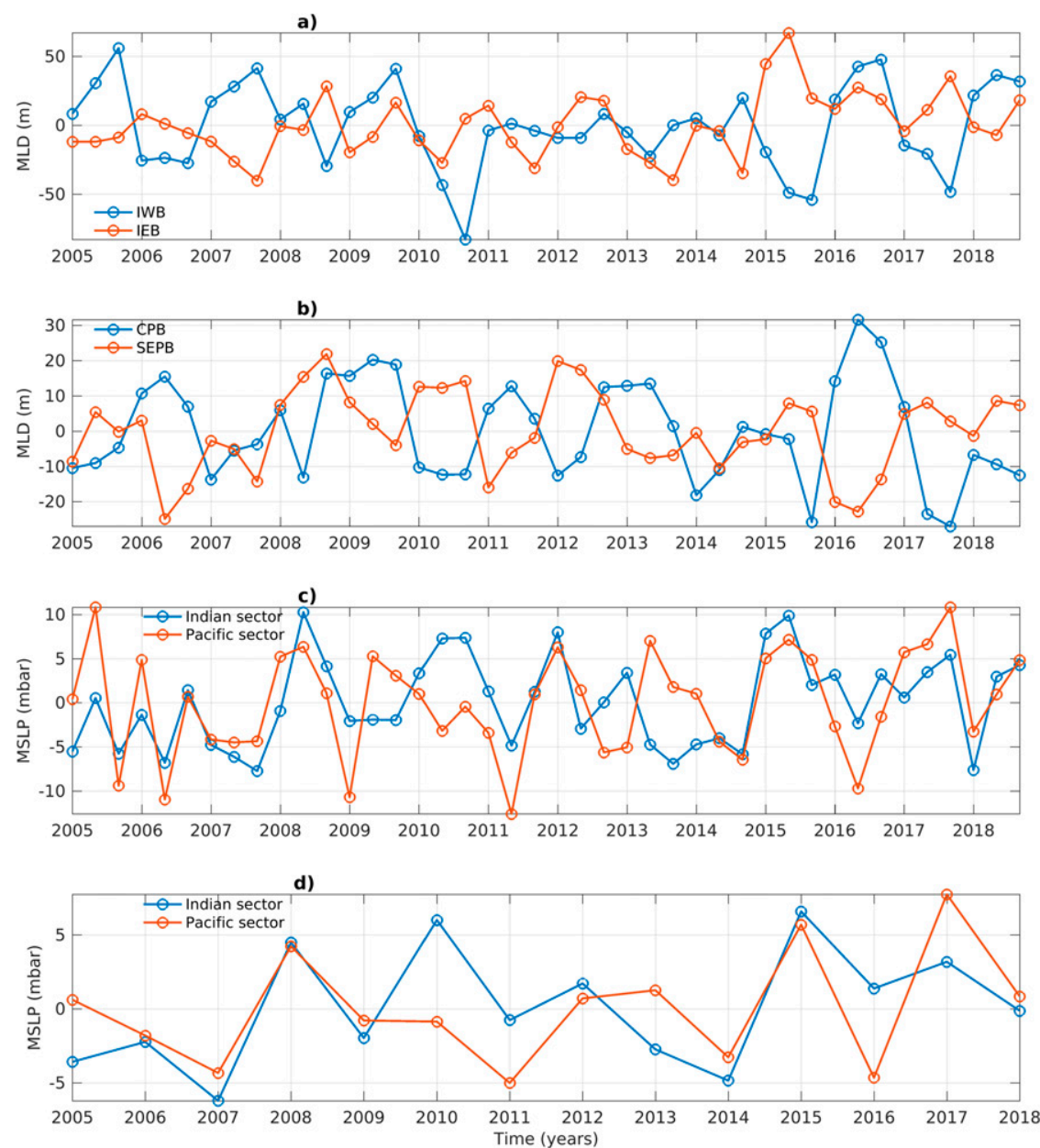

FIG. 8. Wintertime (July-September) MLD anomalies averaged over the (a) IWB (blue) and IEB (red) and (b) CPB (blue) and SEPB (red) (in m); (c) wintertime (July-September) MSLP anomalies (in mbar) averaged over the regions of strongest variance in the Indian and Pacific sector. (d) As in (c), but for wintertime averages of each year.

ocean sectors, numerous other sources of variability, such as advection of heat and salt by the ACC, will weaken the explanatory power of the EOF1. We therefore compare composites of the atmospheric and oceanic conditions in winters with anomalously strong positive MSLP (+MSLP) and anomalously strong negative MSLP (-MSLP) to investigate the mechanisms linking MSLP variability to MLD change. All averages shown in this section are wintertime (July-September) averages.

A scatterplot of the normalized MLD anomalies (averaged over the SAMW boxes under consideration) versus normalized MSLP anomalies (spatially averaged over the region of highest variability in the ocean sector under consideration) shows that anomalous + MSLP drives anomalously deep mixed layers in both the SEPB and IEB, and mostly anomalously shallow mixed layers in the CPB and IWB. The opposite occurs under anomalous -MSLP (Fig. 7). In all boxes the correlation between the MLD anomaly and MSLP anomaly is strong and statistically significant. This out-of-phase MLD variability forming zonal dipoles in both the Indian and Pacific sectors in winters with strong MSLP anomalies is also evident in the time series of wintertime MLD anomalies averaged over the individual SAMW boxes (Fig. 8). This also shows that while there are some differences (e.g., 2010, 2013), on the whole the MSLP anomalies in the Pacific and Indian sectors tend to vary in phase with one another (Figs. 8c,d). This allows us to construct composites of the winters with the strongest anomalies and to examine the spatial structure of MSLP, MLD, wind and Ekman transport anomalies. The three winters chosen with strong + MSLP anomalies in both basins were in 2008, 2015, and 2017, and the three winters with the strongest -MSLP anomalies were in 2007, 2011, and 2016 (Figs. 7 and 8d).

The main feature of the MSLP anomaly maps in years with both strong positive and negative MSLP anomalies are the three centers of strong MSLP anomaly already identified, one in each ocean sector (Figs. 9a,b), with opposite signed anomalies over the Antarctic continent and peninsula. In the regions of SAMW formation the strong + MSLP anomalies are associated with deep (shallow) MLs in the eastern (western) parts 

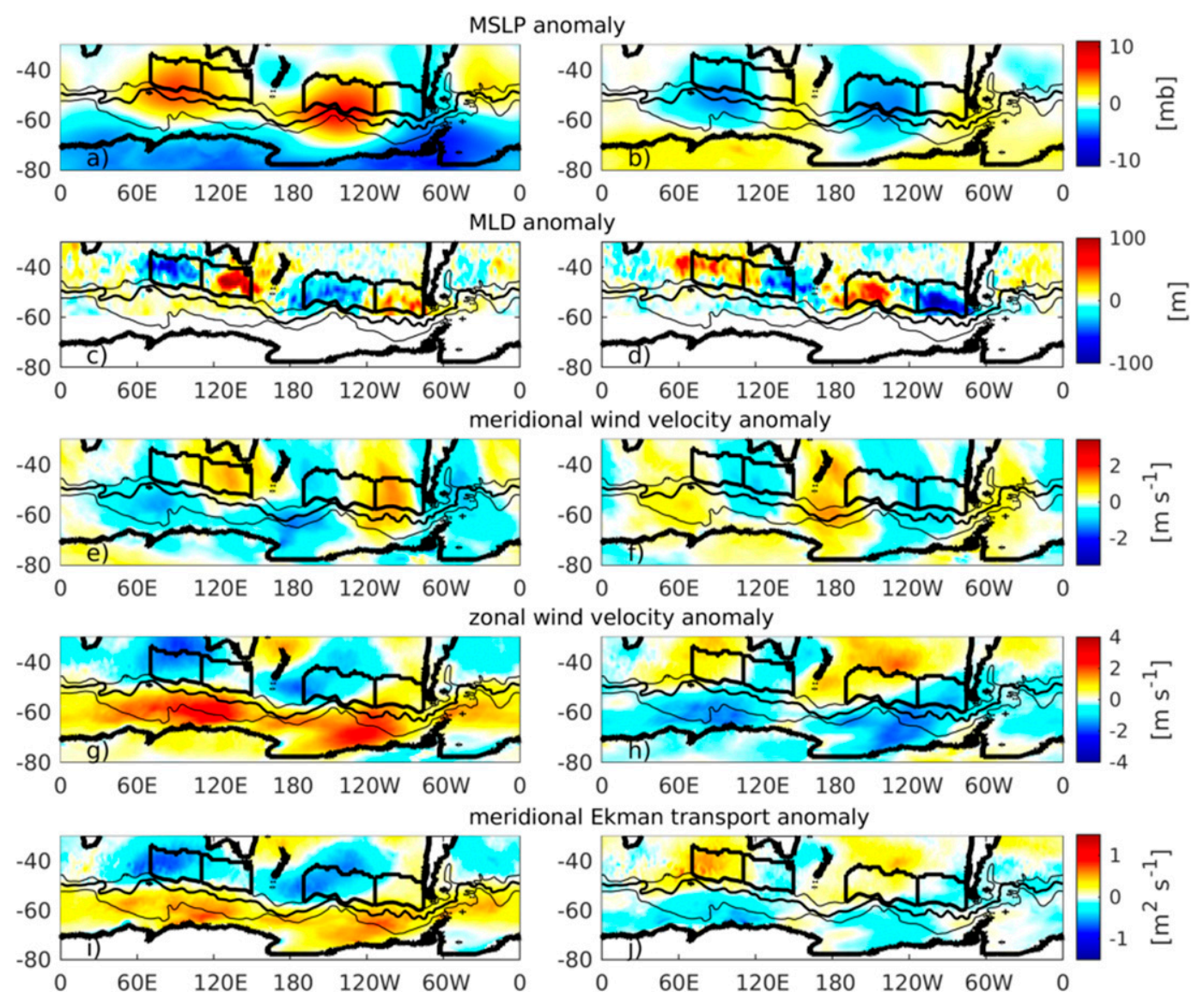

FIG. 9. Composites of wintertime anomalies averaged over (left) years with strong positive July-September MSLP anomalies $(2008,2015$, and 2017) and (right) years with strong negative July-September MSLP anomalies (2007, 2011, and 2016) for (a),(b) MSLP (mb), (c),(d) MLD (m), the (e),(f) meridional and (g), (h) zonal component of wind velocity (both $\left.\mathrm{m} \mathrm{s}^{-1}\right)$, and (i),(j) meridional Ekman transport anomaly from ERA5 $\left(\mathrm{m}^{2} \mathrm{~s}^{-1}\right)$.

of the individual ocean sectors (Figs. 9a,c). The opposite holds for the strong - MSLP anomalies (Figs. 9b,d). In both cases the mean wintertime MLD anomalies for these composite years can exceed $100 \mathrm{~m}$. The meridional wind velocity anomalies have the opposite sign on the two flanks of strong MLSP anomalies (Figs. 9e,f). On the eastern flanks of the MSLP anomalies there are strengthened southerly winds (or weakened northerly winds) while on their western flanks there are strengthened northerly winds. While the wind anomalies noted here are unlikely to directly drive a deeper winter MLD (Marshall and Schott 1999), they are associated with changes in the overlying air temperatures (Figs. 11a,b) and the instantaneous winter heat flux (Figs. 10c,d). Additionally we find that winters with strong surface heat loss are typically preceded by April-September entertainment periods with cumulative surface ocean heat loss stronger than on average, especially over the IWB and SEPB where the cumulative heat flux is significantly different from May onward (Figs. 11g-j).

The zonal wind velocity anomalies are strongest poleward of the SAMW formation regions (Figs. 9g,h) and + MSLP anomalies strengthen the westerlies in both the Pacific and Indian sectors. As with the meridional winds, these do not necessarily directly drive deeper mixed layers, but instead increase (or decrease for -MSLP) the cross-isopycnal Ekman transport of cold water in the SAMW formation regions (Figs. 9i,j). This Ekman transport has been identified as an important mechanism influencing SAMW formation and properties (Rintoul and England 2002) and may contribute, alongside the surface heat fluxes, to the observed changes in ocean surface temperature anomalies (Figs. 11c,d).

All these changes strongly impact the wintertime surface ocean heat flux in all SAMW formation regions. In each of the three ocean sectors, a +MSLP (-MSLP) anomaly is associated with an increased (decreased) surface ocean heat loss in the eastern part, and decreased (increased) surface ocean heat loss in the western part of the ocean sector (Figs. 10c,d). This pattern closely resembles wintertime surface ocean heat flux anomalies that develop during +SAM (-SAM) events (Fig. 10a). In the Pacific sector and western Atlantic, a very similar pattern of wintertime surface ocean heat flux develops during positive (negative) ENSO events (Fig. 10b).

The +MSLP anomalies are associated with the near-surface (at 5-m depth) salinity increase in the Indian sector and salinity decrease in the central Pacific (Figs. 11e,f). The near-surface 

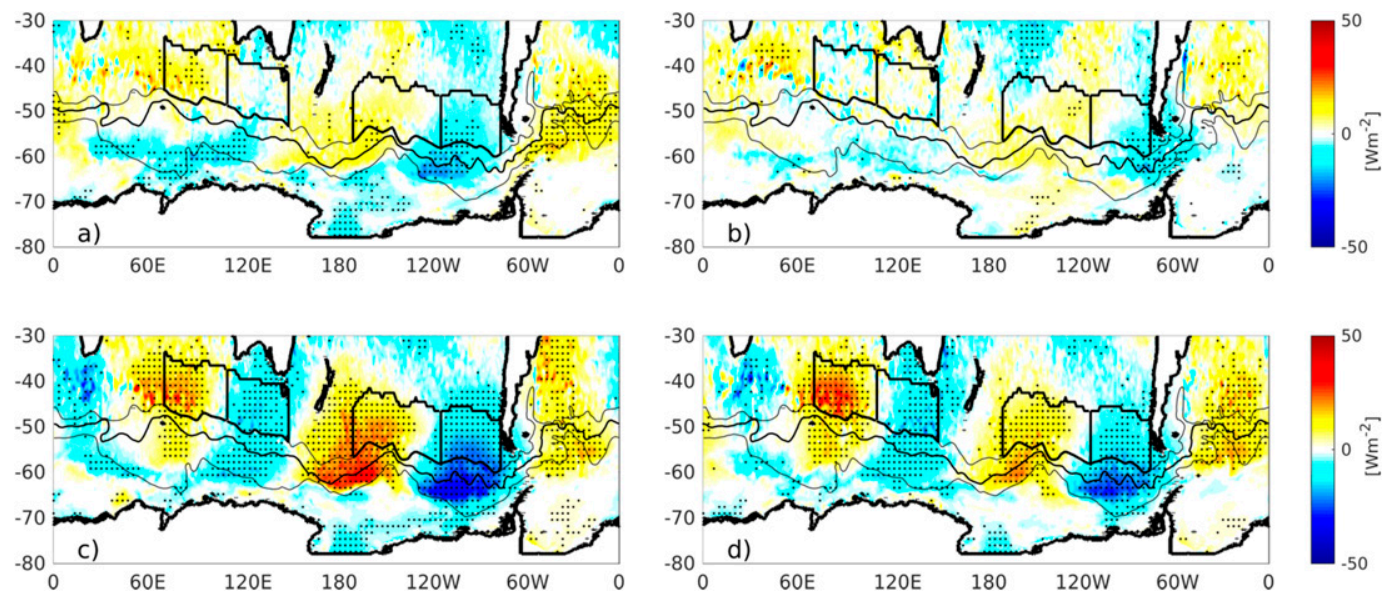

FIG. 10. The linear regression coefficients of the net air-sea heat flux in winter (July-September) on (a) the SAM index, (b) the Niño-3.4 index, (c) the MSLP averaged over the box of strong pressure variability in the Pacific sector, and (d) the MSLP averaged over the box of strong pressure variability in the Indian sector, all with the trend and the seasonal signal removed (in $\mathrm{W} \mathrm{m}^{-2}$ ). Stippling indicates a statistically significant correlation at the $95 \%$ level. Negative values indicate ocean heat loss.

salinity anomalies tend to have the opposite sign in the case of + MSLP and -MSLP anomalies (Fig. 11f). These anomalies generally display less spatial coherence and do not exhibit the clear cross-basin dipole pattern seen in the air temperature, and to a lesser extent the near-surface ocean temperature. This suggests that while Ekman transport may contribute to the SAMW regional properties it is probably not as significant as surface heat fluxes in driving the dipole patterns.

Analyzing the Pacific SAMW formation regions, Meijers et al. (2019) showed that advective processes were more important in modifying SAMW temperature and salinity than in modifying the SAMW thickness. This may also account for the weaker temperature and salinity responses to MSLP anomalies seen here. We examine this further in the following section.

\section{d. Interannual variability of SAMW properties}

To gain further insight into the importance and time scale of advective processes that modify the SAMW properties in their formation regions, we consider Hovmöller diagrams of the isopycnal depth anomalies in the SAMW density range (with the time-mean and seasonal signal removed), averaged meridionally over the $12^{\circ}$ wide band located equatorward of their respective monthly mean outcrop positions (Fig. 12). Particularly large isopycnal depth anomalies were observed for $\sigma_{\theta}=26.8 \mathrm{~kg} \mathrm{~m}^{-3}$ (hereafter $\sigma_{26.8}$ ) in the Indian sector and for $\sigma_{\theta}=26.95 \mathrm{~kg} \mathrm{~m}^{-3}$ (hereafter $\sigma_{26.95}$ ) in the Pacific sector. For both isopycnals, depth anomalies can exceed $\pm 100 \mathrm{~m}$ in some years. The strongest anomalies developed around approximately $120^{\circ} \mathrm{E}$ in the Indian sector and $120^{\circ} \mathrm{W}$ in the Pacific sector (Fig. 12), the locations where the wintertime MLD anomalies are strongly correlated with the MSLP anomalies (Fig. 6). Both $\sigma_{26.8}$ (in the Indian sector) and $\sigma_{26.95}$ (in the Pacific sector) isopycnal depth anomalies were anomalously shallow in the early Argo period, followed by the isopycnal deepening that was especially strong between 2014 and 2017 in the Pacific sector (Figs. 12a,b). In some cases strong isopycnal depth anomalies are advected eastward by the ACC. In the Indian Ocean, a weak propagating signal of $\sigma_{26.8}$ depth anomalies is evident between the Kerguelen Plateau $\left(70^{\circ} \mathrm{E}\right)$ and the South Tasman Rise $\left(150^{\circ} \mathrm{E}\right)$ over much of the time series. At the latter location complex topography and strong advection of warm and salty subtropical water from the Tasman Sea (Herraiz-Borreguero and Rintoul 2011) likely both contribute to the abrupt termination of the propagating signal.

In the Pacific sector two episodes of eastward propagation of $\sigma_{26.95}$ isopycnal depth anomaly stand out. A particularly strong $\sigma_{26.95}$ depth anomaly developed in 2015, when the isopycnal deepened in the $\mathrm{CPB}$, and this anomaly propagated eastward, reaching the SEPB in 2016, and two years later it was advected east of Drake Passage (Fig. 12b). The deepening of the $\sigma_{26.95}$ isopycnal occurred at the time when the wintertime MSLP in the central Pacific was anomalously negative (Figs. 8c,d), the volume of the newly formed water in the CPB was anomalously large (Fig. 3d), the wintertime ML in the CPB was anomalously deep (Fig. 8b) and the SAMW layer in the CPB was anomalously thick (Fig. 14b). This strong isopycnal depth anomaly was also associated with a strong positive temperature anomaly and in 2015/16 the SAMW in the CPB and SEPB was anomalously warm, likely associated with a very strong El Niño event (Fig. 13). This positive temperature anomaly was advected eastward in the SAMW density range $\left(\sigma_{\theta}=26.8\right.$ $27.0 \mathrm{~kg} \mathrm{~m}^{-3}$ ), so that in years $2015-17$ it reached the SEPB (Fig. 13). The advective time scale for this anomaly from the central to the southeast Pacific SAMW formation region is approximately one year, a value consistent with Cerovečki et al. (2019) and Meijers et al. (2019). Such strong eastward propagating isopycnal depth and temperature anomalies in the SAMW density range may precondition the SAMW formation in the subsequent winter in the formation regions located farther east by changing the upper ocean stratification. The $\sigma_{26.95}$ depth anomaly averaged over the SEPB longitude range is strongly correlated $(r=0.75)$ with the anomaly averaged over the CPB longitude range one year earlier. In contrast, the 

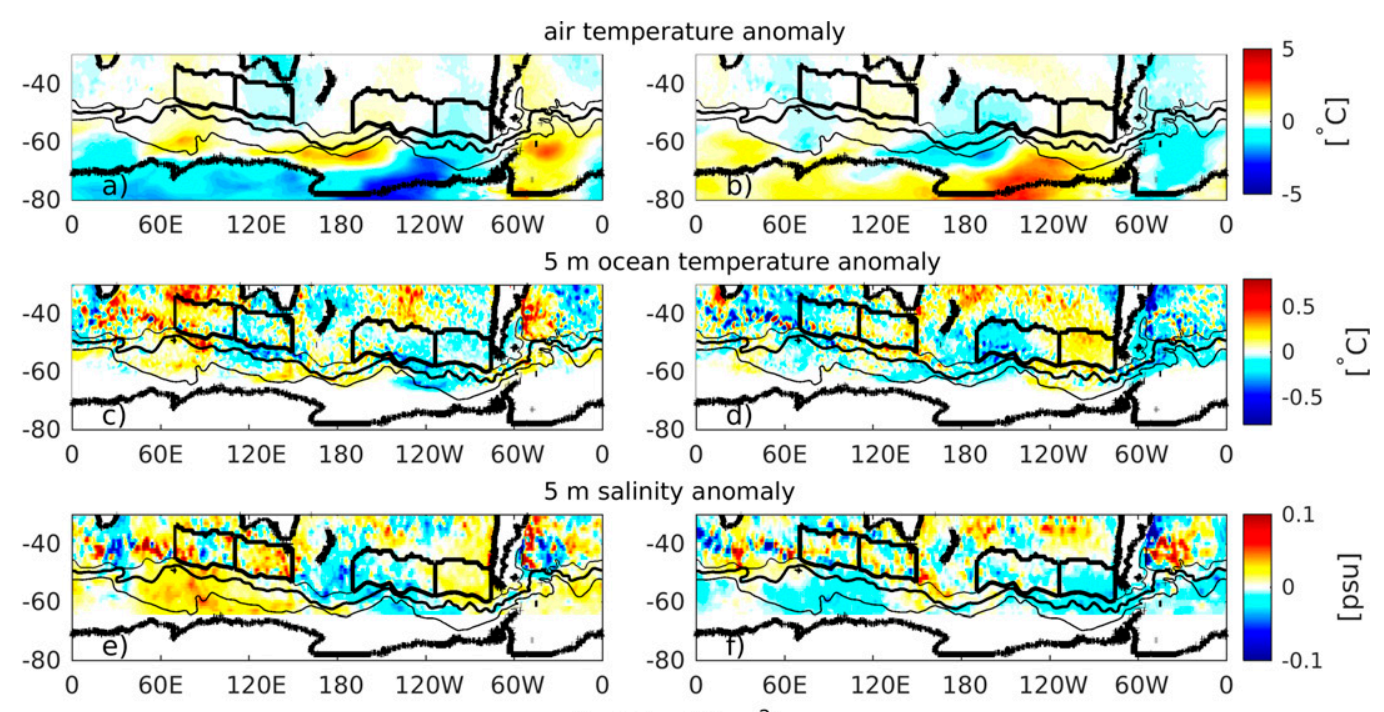

inity anomaly
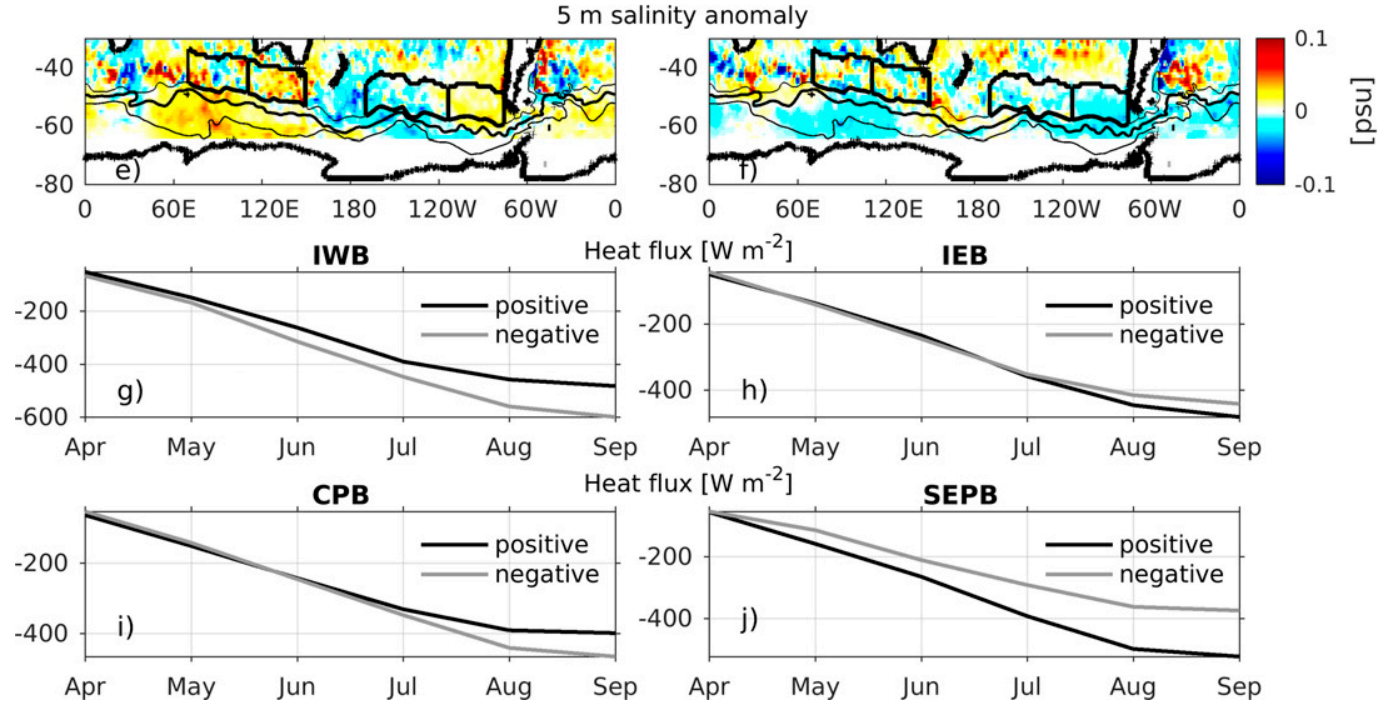

FIG. 11. As in Fig. 9, except for (a),(b) 2-m air temperature anomaly $\left({ }^{\circ} \mathrm{C}\right),(\mathrm{c}),(\mathrm{d})$ ocean near-surface temperature anomaly from the top layer of RG-Argo at 5-m depth $\left({ }^{\circ} \mathrm{C}\right)$, and (e),(f) near-surface salinity anomaly from the top layer of RG-Argo at 5-m depth (psu). Cumulative monthly mean surface ocean heat flux from April to September subsequently time averaged over years with strong positive (shown as a thick black line) and strong negative wintertime MSLP anomalies (shown as a thick gray line, while years are given in Fig. 9), spatially averaged over the (g) IWB, (h) IEB, (i) CPB, and (j) SEPB. Negative values indicate surface ocean heat loss (in $\mathrm{W} \mathrm{m}^{-2}$ ).

correlation between the $\sigma_{26.8}$ depth anomaly in the IWB and in the IEB one year later is much weaker (0.41), in agreement with the much weaker propagating signal shown in Fig. 12a.

The other episode of the eastward propagating $\sigma_{26.95}$ isopycnal depth anomaly in the Pacific shows a shoaling that started in 2007 in the CPB, intensified in 2008, and arrived at the SEPB in 2009 (Fig. 12b). Shoaling was associated with a negative temperature anomaly (Fig. 13b). Note that these temperature anomalies are within an isopycnal range, and so should not be interpreted as change at a depth level. In 2007/08, for example, there is surface warming associated with the shoaling, which on an isopycnal in this region will appear as a cooling under a "pure warming" type scenario in the framework of Bindoff and McDougall (1994).

\section{Conclusions}

The interannual variability of deep wintertime mixed layers and SAMW volume has been analyzed using a gridded Argo product (RG-Argo) and contextualized using ERA5 reanalysis atmospheric fields, for the years $2005-18$. The dominant pattern of interannual variability of both deep wintertime mixed layers and SAMW volume is a dipole that develops in each of the three Southern Ocean sectors in winters with anomalously strong MSLP anomalies (Fig. 1). In winter, one quasi-stationary center of strong monthly MSLP variability develops north of the SAF in each of the three ocean sectors and we find a strong relationship between the MSLP variability and the formation of dipoles in MLD in SAMW formation sites in the Indian and Pacific sectors (Fig. 6). The MSLP variability is much stronger in the Indian and Pacific sectors (centered at approximately $100^{\circ} \mathrm{E}$ and $150^{\circ} \mathrm{W}$ ) than in the Atlantic sector (centered at approximately $25^{\circ} \mathrm{W}$ ). While the year to year variabilities of the MSLP in these three centers do not necessarily covary with one another, in years with strong MSLP anomalies they do tend to be of the same sign in all three ocean sectors (Figs. 9a,b).

The meridional wind anomalies introduced by these MSLP anomalies are of the opposite sign on the two flanks of each center of the MSLP anomaly. Thus, strong positive wintertime MSLP anomalies strengthen the southerly winds in the eastern part of 

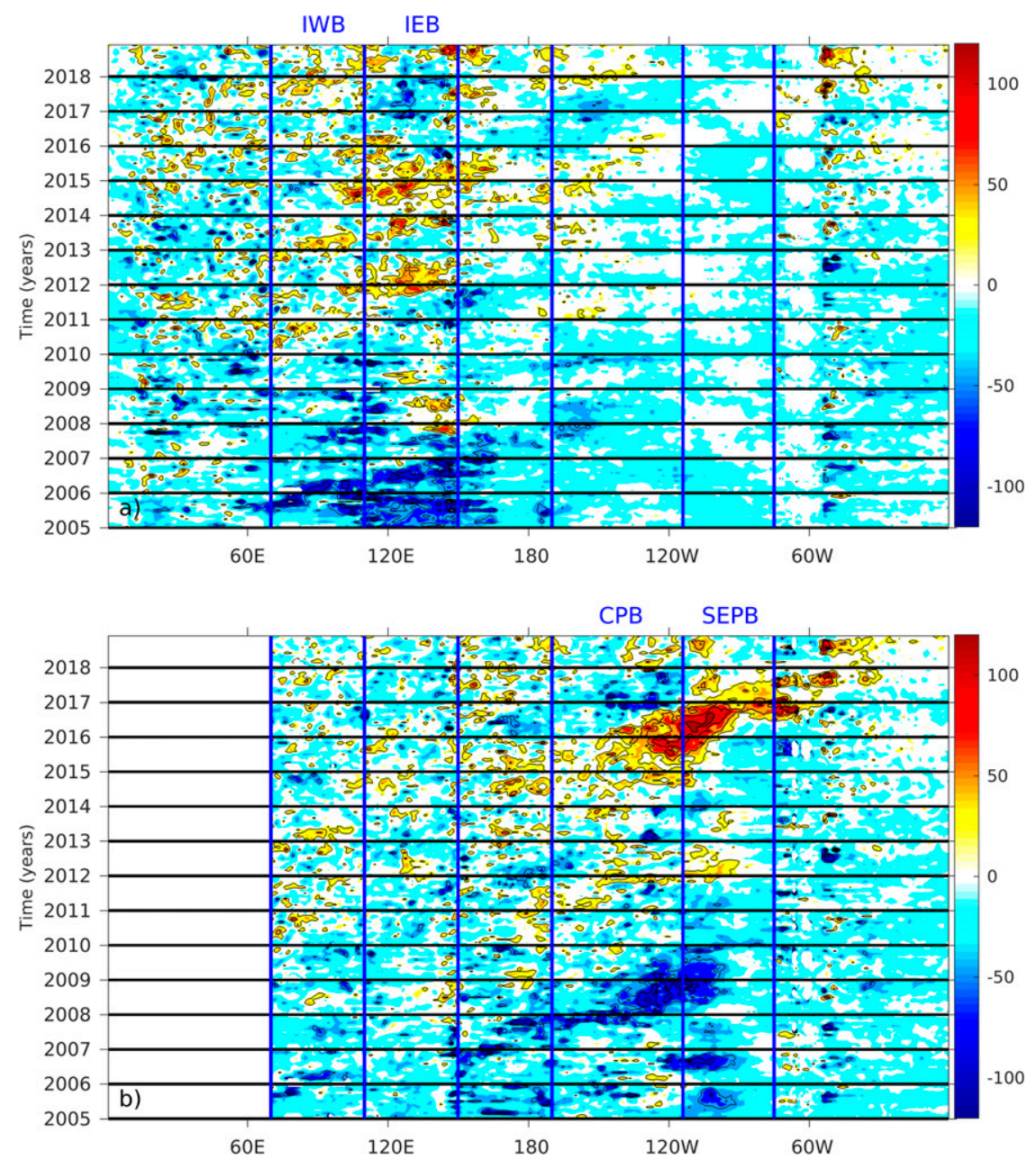

FIG. 12. Time-longitude diagram of the monthly mean isopycnal depth anomaly (with the time-mean and seasonal signal removed) averaged meridionally over $12^{\circ}$ wide band located north of the position of monthly mean isopycnal outcrop, for isopycnals within the SAMW density range (a) in the Indian Ocean $\left(\sigma_{\theta}=26.8 \mathrm{~kg} \mathrm{~m}^{-3}\right)$ and (b) in the Pacific Ocean $\left(26.95 \mathrm{~kg} \mathrm{~m}^{-3}\right)$, where the latter is shown only east of the Kerguelen Plateau. Vertical blue lines indicate the longitudinal range of each of the four SAMW boxes shown in Fig. 1. Data are from RG-Argo. Values are in meters, with a contour interval of $30 \mathrm{~m}$, and the zero contour is omitted.

each ocean sector, decreasing the air temperature, increasing the surface ocean heat loss, deepening the wintertime mixed layers, and increasing the formation of SAMW. In contrast, on the western flank of the positive wintertime MSLP anomalies northerly winds increase the air temperature, weaken the surface ocean heat loss, shoal the wintertime mixed layers, and decrease SAMW formation rates (Figs. 9c,h and 11a,b,g-j). The positive wintertime MSLP anomalies also increase zonal winds immediately poleward of the SAMW formation regions in all three ocean sectors, especially in the eastern parts of the Indian and Pacific sectors. This will increase equatorward Ekman transport of cold water, driving convection in SAMW formation regions, which is an important process of SAMW formation (Rintoul and England 2002), further augmenting SAMW formation by cooling the eastern parts of each ocean basin. The effects of the strong negative wintertime pressure anomalies are largely opposite to these associated with the positive wintertime pressure anomalies. In this way, both strong positive and strong negative wintertime MSLP anomalies drive a dipole pattern in deep wintertime mixed layer distribution and the SAMW formation in each of the three ocean sectors (although the one in the Atlantic is much weaker than in the Pacific and Indian Ocean sectors). This dipole pattern implies that in years with the preferential formation of colder and denser varieties of SAMW in the eastern parts of the Indian and Pacific dipole, the formation of warmer and lighter varieties of SAMW in the western part of both dipoles is anomalously weak, amplifying the net cooling and densification in each ocean sector. Conditions reverse in years with the preferential formation of warmer and lighter varieties of SAMW. When integrated over the whole basin the dipoles tend to cancel one another, leading basinwide SAMW formation interannual variability to be lower than that of the two formation pools in each basin (Figs. 3c-e). Given the zonal property gradient of SAMW 

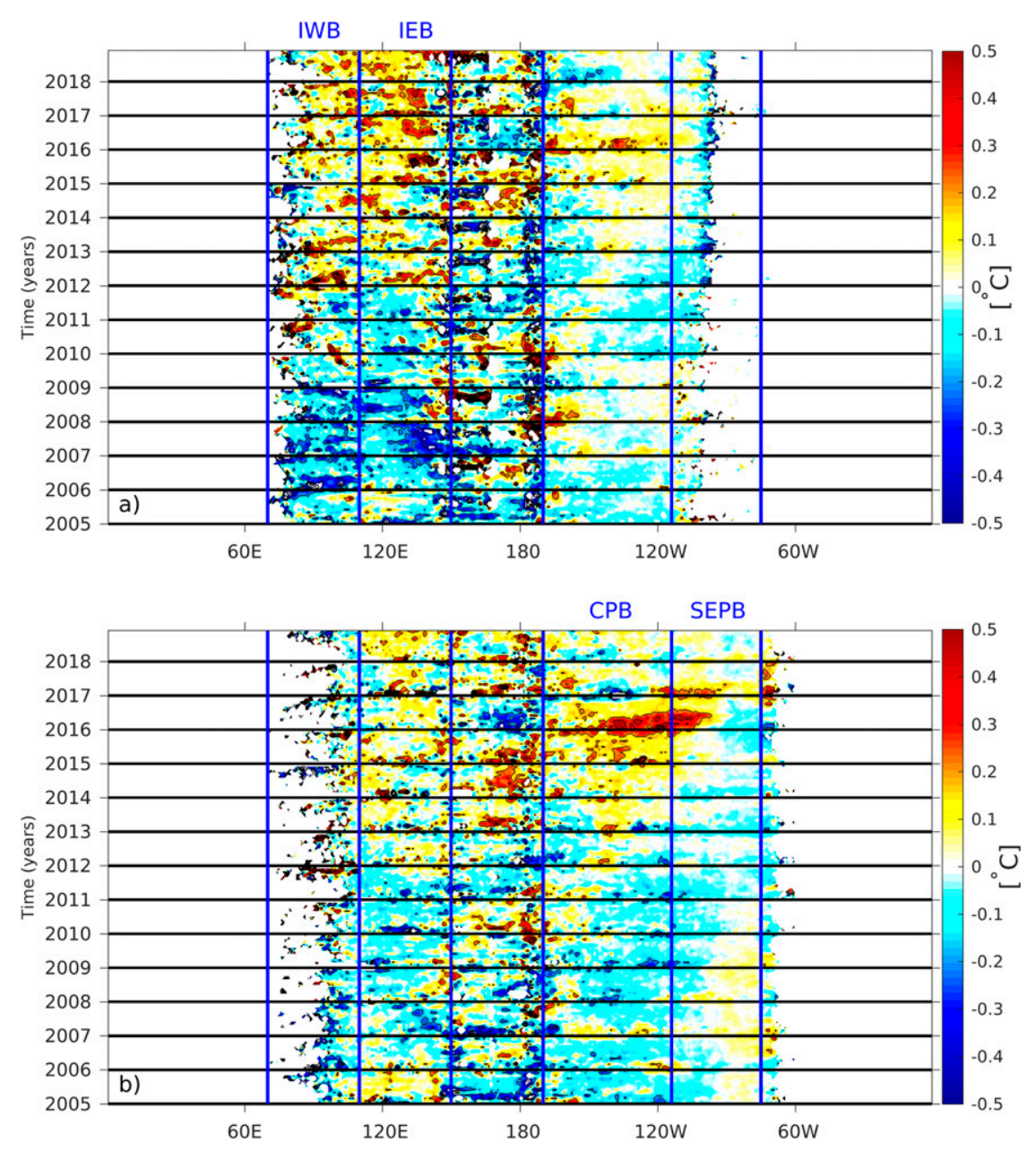

FIG. 13. As in Fig. 12, but for the potential temperature vertically averaged over the low PV $\left.\left(\mathrm{PV}<40 \times 10^{-12} \mathrm{~m}^{-1} \mathrm{~s}\right)^{-1}\right)$ layer in the $\sigma_{\theta}$ ranges (a) $26.7-26.9$ and (b) $26.8-27.0 \mathrm{~kg} \mathrm{~m}^{-3}$, and averaged meridionally over a $12^{\circ}$-wide band located north of the monthly mean outcrop position of the lightest density considered (in ${ }^{\circ} \mathrm{C}$ ). Contour interval is $0.2^{\circ} \mathrm{C}$, with the zero contour omitted.

formation across each basin this may mean that considering the basin formation of either the Indian or Pacific sectors as a whole masks considerable interannual property variability.

The SAMW thickness anomalies associated with both the wintertime SAM and ENSO also have a dipole pattern in the Indian and Pacific sectors, although ENSO is only significant in the Pacific formation regions. A strong wintertime positive (negative) SAM increases (decreases) the MSLP in all three centers of high variability, giving rise to a dipole pattern in zonal distribution of wintertime MLs in each of the three ocean sectors (Fig. 5). Meijers et al. (2019) showed that when wintertime SAM and ENSO are in phase in the Pacific, the wind anomalies that develop in response to each of them enhance each other, but when out of phase they tend to cancel. Since this does not apply in the Indian sector, it will tend to reduce the degree of covariability between the centers of MSLP. During the Argo time period, the largest difference between the SAMW formation in the Indian and Pacific sector occurred in 2016. The difference can at least in part be attributed to the extreme El Niño event in
2015/16 (Stuecker et al. 2017), since ENSO has a strong teleconnection to the atmospheric and surface ocean conditions in the Pacific, but not in the Indian sector (Turner 2004; Fogt and Bromwich 2006; Meijers et al. 2019; Naveira Garabato et al. 2009; Vivier et al. 2010). Overall we find that while the SAM and ENSO contribute significantly to the MSLP variability driving the variance in SAMW MLD and properties, but do not entirely explain the MSLP variability by themselves.

The eastward propagation of temperature, salinity, and volume anomalies in the SAMW density range also acts to weaken the SAMW covariability in the Indian and Pacific sectors. The eastward propagating anomalies act to precondition SAMW formation downstream, adding a degree of "memory" to the system. The strong isopycnal depth variability in the SAMW density range develops in the longitude ranges where the wintertime MLD anomalies are well correlated with the wintertime MSLP anomalies. While the eastward propagation was generally weak in the Indian sector, two episodes of eastward propagation of the $\sigma_{\theta}=26.95 \mathrm{~kg} \mathrm{~m}^{-3}$ isopycnal were observed in the Pacific 

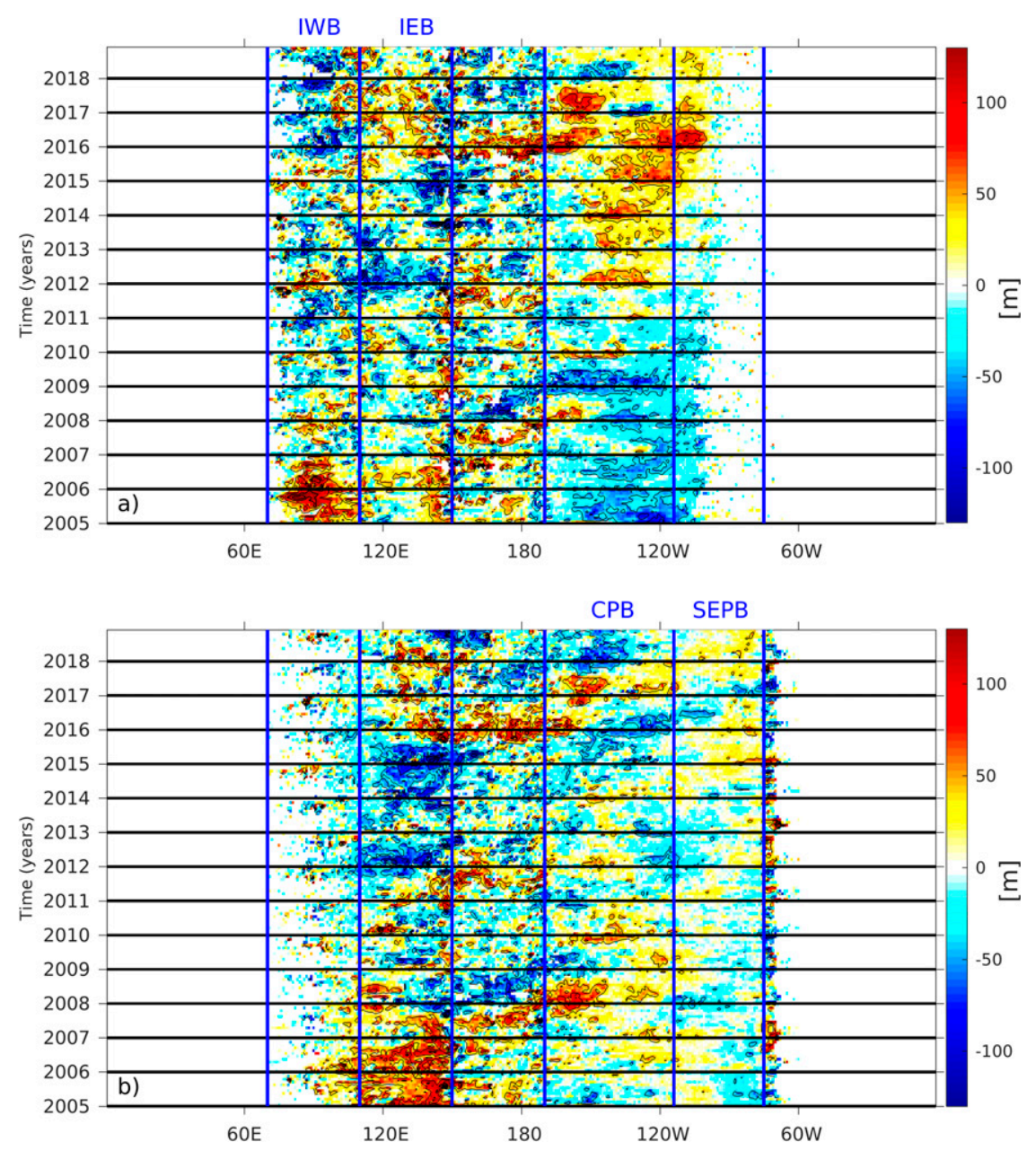

FIG. 14. As in Fig. 12, but for the layer thickness (in m). Contour interval is $15 \mathrm{~m}$, starting from $5 \mathrm{~m}$.

sector. Isopycnal deepening that developed in the central Pacific during the extreme El Niño event in 2015/16 was advected to the SEPSAMW formation region a year later, and east of the Drake Passage two years later. It was associated with a strong positive temperature anomaly. A strong shoaling of the $\sigma_{26.95}$ isopycnal that developed in 2008 in the CPB propagated eastward to the SEPB in 2009. Both events illustrate the importance of advective effects in governing the interannual variability of SAMW volume and properties. However, the degree to which such propagation and preconditioning acts to influence subsequent downstream formation versus the impact of local forcing remains to be quantified and should be a focus for future research.

Finally, the strong interannual variability of SAMW volume and properties that we show are important because they strongly modify the upper ocean heat and carbon content. In recent decades, regional shifts in MSLP and the related changes in surface winds were shown to play a very important role in the interannual to decadal variability of the Southern Ocean carbon sink (Keppler and Landschützer 2019). The degree to which such large-scale shifts in the MSLP impact the mechanism linking them to SAMW formation should be closely examined. Changes to this coupling have the potential to significantly alter the ocean uptake of heat and carbon. Therefore understanding the mechanisms that govern the variability of SAMW volume and properties is also necessary to understanding how they may change in the future under climate forcing scenarios.

Acknowledgments. IC received support from National Science Foundation Award OCE-1658001 and NASA Grant 80NSSC19K1115. IC would like to thank Mark Bourassa for particularly helpful suggestions. The Niño-3.4 index has been obtained from http://www.cpc.ncep.noaa.gov/data/indices/ sstoi.indices, while the SAM index has been retrieved from https://climatedataguide.ucar.edu/climate-data/marshall-southernannular-mode-sam-index-station-based.

\section{REFERENCES}

Bindoff, N. L., and T. J. McDougall, 1994: Diagnosing climate change and ocean ventilation using hydrographic data. J. Phys. Oceanogr., 
24, 1137-1152, https://doi.org/10.1175/1520-0485(1994)024<1137: DCCAOV $>2.0 . \mathrm{CO} ; 2$.

Cerovečki, I., A. J. Meijers, M. R. Mazloff, S. T. Gille, V. M. Tamsitt, and P. R. Holland, 2019: The effects of enhanced sea ice export from the Ross Sea on recent cooling and freshening of the southeast Pacific. J. Climate, 32, 2013-2035, https:// doi.org/10.1175/JCLI-D-18-0205.1.

Close, S. E., A. C. Naveira Garabato, E. L. McDonagh, B. A. King, M. Biuw, and L. Boehme, 2013: Control of mode and intermediate water mass properties in Drake Passage by the Amundsen Sea low. J. Climate, 26, 5102-5123, https://doi.org/ 10.1175/JCLI-D-12-00346.1.

Connolley, W. M., 1997: Variability in annual mean circulation in southern high latitudes. Climate Dyn., 13, 745-756, https:// doi.org/10.1007/s003820050195.

Davis, X. J., L. M. Rothstein, W. K. Dewar, and D. Menemenlis, 2011: Numerical investigations of seasonal and interannual variability of North Pacific Subtropical Mode Water and its implications for Pacific climate variability. J. Climate, 24, 2648-2665, https://doi.org/10.1175/2010JCLI3435.1.

ECMWF, 2017: ERA5 reanalysis. Research Data Archive at the National Center for Atmospheric Research, Computational and Information Systems Laboratory, accessed 18 March 2019, https://doi.org/10.5065/D6X34W69.

Fogt, R. L., and D. H. Bromwich, 2006: Decadal variability of the ENSO teleconnection to the high-latitude South Pacific governed by coupling with the southern annular mode. J. Climate, 19, 979-997, https://doi.org/10.1175/JCLI3671.1.

Gao, L., S. R. Rintoul, and W. Yu, 2018: Recent wind-driven change in Subantarctic Mode Water and its impact on ocean heat storage. Nat. Climate Change, 8, 58-63, https://doi.org/ 10.1038/s41558-017-0022-8.

Herraiz-Borreguero, L., and S. R. Rintoul, 2011: Subantarctic Mode Water: Distribution and circulation. Ocean Dyn., 61, 103-126, https://doi.org/10.1007/s10236-010-0352-9.

Hobbs, W. R., and M. N. Raphael, 2010: Characterizing the zonally asymmetric component of the SH circulation. Climate Dyn., 35, 859-873, https://doi.org/10.1007/s00382-009-0663-z.

Jones, D. C., A. J. S. Meijers, E. Shuckburgh, J.-B. Sallée, P. Haynes, E. K. McAufield, and M. R. Mazloff, 2016: How does Subantarctic Mode Water ventilate the Southern Hemisphere subtropics? J. Geophys. Res. Oceans, 121, 6558-6582, https://doi.org/10.1002/ 2016JC011680.

Keppler, L., and P. Landschützer, 2019: Regional wind variability modulates the Southern Ocean carbon sink. Sci. Rep., 9, 73847393, https://doi.org/10.1038/s41598-019-43826-y.

Koch-Larrouy, A., R. Morrow, T. Penduff, and M. Juza, 2010: Origin and mechanism of Subantarctic Mode Water formation and transformation in the southern Indian Ocean. Ocean Dyn., 60, 563-583, https://doi.org/10.1007/s10236010-0276-4.

Marshall, G., 2003: Trends in the southern annular mode from observations and reanalyses. J. Climate, 16, 4134-4143, https://doi.org/ 10.1175/1520-0442(2003)016<4134:TITSAM >2.0.CO;2.

Marshall, J., and F. Schott, 1999: Open-ocean convection: Observations, theory, and models. Rev. Geophys., 37, 1-64, https://doi.org/10.1029/ 98RG02739.

McCartney, M., 1977: Subantarctic mode water. Deep-Sea Res., 24, 103-119.

_ 1982: The subtropical recirculation of mode waters. J. Mar. Res., 40, 427-464.

Meijers, A., I. Cerovečki, B. A. King, and V. M. Tamsitt, 2019: A see-saw in Pacific Subantarctic Mode Water formation driven by atmospheric modes. Geophys. Res. Lett., 46, 13 152-13160, https://doi.org/10.1029/2019GL085280.

Meredith, M. P., A. C. N. Garabato, A. L. Gordon, and G. C. Johnson, 2008: Evolution of the deep and bottom waters of the Scotia Sea, Southern Ocean, during 1995-2005. J. Climate, 21, 3327-3343, https://doi.org/10.1175/2007JCLI2238.1.

Naveira Garabato, A. C., L. Jullion, D. P. Stevens, K. J. Heywood, and B. A. King, 2009: Variability of Subantarctic Mode Water and Antarctic Intermediate Water in the Drake Passage during the late-twentieth and early-twenty-first centuries. J. Climate, 22, 3661-3688, https://doi.org/10.1175/2009JCLI2621.1.

Orsi, A. H., T. Whitworth III, and W. D. Nowlin Jr., 1995: On the meridional extent and fronts of the Antarctic Circumpolar Current. Deep-Sea Res., 42, 641-673, https://doi.org/10.1016/ 0967-0637(95)00021-W.

Portela, E., N. Kolodziejczyk, C. Maes, and V. Thierry, 2020: Interior water-mass variability in the Southern Hemisphere oceans during the last decade. J. Phys. Oceanogr., 50, 361-381, https://doi.org/10.1175/JPO-D-19-0128.1.

Raphael, M. N., 2004: A zonal wave 3 index for the Southern Hemisphere. Geophys. Res. Lett., 31, L23212, https://doi.org/ 10.1029/2004GL020365.

Rintoul, S. R., and M. H. England, 2002: Ekman transport dominates local air-sea fluxes in driving variability of Subantarctic Mode Water. J. Phys. Oceanogr., 32, 1308-1321, https://doi.org/10.1175/ 1520-0485(2002)032<1308:ETDLAS >2.0.CO;2.

Roemmich, D., and J. Gilson, 2009: The 2004-2008 mean and annual cycle of temperature, salinity, and steric height in the global ocean from the Argo program. Prog. Oceanogr., 82, 81100, https://doi.org/10.1016/j.pocean.2009.03.004.

Sabine, C. L., and Coauthors, 2004: The oceanic sink for anthropogenic $\mathrm{CO}_{2}$. Science, 305, 367-371, https://doi.org/10.1126/ science.1097403.

Sallée, J., K. Speer, and S. Rintoul, 2010a: Zonally asymmetric response of the Southern Ocean mixed-layer depth to the southern annular mode. Nat. Geosci., 3, 273-279, https://doi.org/10.1038/ngeo812.

,,---1, and S. Wijffels, 2010b: Southern Ocean thermocline ventilation. J. Phys. Oceanogr., 40, 509-529, https:// doi.org/10.1175/2009JPO4291.1.

Sarmiento, J. L., N. Gruber, M. A. Brzezinski, and J. P. Dunne, 2004: High-latitude controls of thermocline nutrients and low latitude biological productivity. Nature, 427, 56-60, https:// doi.org/10.1038/nature02127.

Stuecker, M. F., C. M. Bitz, and K. C. Armour, 2017: Conditions leading to the unprecedented low Antarctic sea ice extent during the 2016 austral spring season. Geophys. Res. Lett., 44, 9008-9019, https://doi.org/10.1002/2017GL074691.

Tamsitt, V., I. Cerovečki, S. Josey, and S. T. Gille, 2020: Mooring observations of air-sea heat fluxes in two Subantarctic Mode Water formation regions. J. Climate, 33, 2757-2777, https:// doi.org/10.1175/JCLI-D-19-0653.1.

Turner, J., 2004: The El Niño-Southern Oscillation and Antarctica. Int. J. Climatol., 24, 1-31, https://doi.org/10.1002/joc.965.

van Loon, H., and R. Jenne, 1972: The zonal harmonic standing waves in the Southern Hemisphere. J. Geophys. Res., 77, 9921003, https://doi.org/10.1029/JC077i006p00992.

Vivier, F., D. Iudicone, F. Busdraghi, and Y.-H. Park, 2010: Dynamics of sea-surface temperature anomalies in the Southern Ocean diagnosed from a 2D mixed-layer model. Climate Dyn., 34, 153-184, https://doi.org/10.1007/s00382-009-0724-3.

Wong, A. P. S., N. L. Bindoff, and J. A. Church, 1999: Large-scale freshening of intermediate waters in the Pacific and Indian Oceans. Nature, 400, 440-443, https://doi.org/10.1038/22733. 